\title{
Memory T cell-driven differentiation of naive cells impairs adoptive immunotherapy
}

\author{
Christopher A. Klebanoff, ${ }^{1,2}$ Christopher D. Scott, ${ }^{2}$ Anthony J. Leonardi, ${ }^{2}$ Tori N. Yamamoto, ${ }^{2,3}$ Anthony C. Cruz, ${ }^{4}$ Claudia Ouyang, ${ }^{4}$ \\ Madhu Ramaswamy, ${ }^{4,5}$ Rahul Roychoudhuri, ${ }^{2}$ Yun Ji, ${ }^{2,6}$ Robert L. Eil, ${ }^{2}$ Madhusudhanan Sukumar, ${ }^{2}$ Joseph G. Crompton, ${ }^{2}$ \\ Douglas C. Palmer, ${ }^{2}$ Zachary A. Borman, ${ }^{2}$ David Clever, ${ }^{2,7}$ Stacy K. Thomas, ${ }^{4}$ Shashankkumar Patel, ${ }^{2,8}$ Zhiya Yu, ${ }^{2}$ \\ Pawel Muranski, ${ }^{2,9}$ Hui Liu, ${ }^{10}$ Ena Wang, ${ }^{10,11}$ Francesco M. Marincola, ${ }^{10,11}$ Alena Gros, ${ }^{2}$ Luca Gattinoni, ${ }^{2,6}$
} Steven A. Rosenberg, ${ }^{2}$ Richard M. Siegel, ${ }^{4}$ and Nicholas P. Restifo ${ }^{2}$

${ }^{1}$ Clinical Investigator Development Program and ${ }^{2}$ Center for Cancer Research, National Cancer Institute (NCI), NIH, Bethesda, Maryland, USA. ${ }^{3}$ Immunology Graduate Group, University of Pennsylvania, Philadelphia, Pennsylvania, USA. 'Autoimmunity Branch, National Institute of Arthritis and Musculoskeletal and Skin Diseases (NIAMS), NIH, Bethesda, Maryland, USA. ${ }^{5}$ Medlmmune, Gaithersburg, Maryland, USA. ${ }^{6}$ Experimental Transplantation and Immunology Branch, NCI, NIH, Bethesda, Maryland, USA. ${ }^{7}$ Medical Scientist Training Program, The Ohio State University College of Medicine, Columbus, Ohio, USA. ${ }^{8}$ Lombardi Comprehensive Cancer Center, Georgetown University, Washington, DC, USA. ${ }^{9}$ National Heart, Lung, and Blood Institute, and ${ }^{10}$ Infectious Disease and Immunogenetics Section, Department of Transfusion Medicine, Clinical Center, NIH, Bethesda, Maryland, USA. "'Sidra Medical and Research Centre, Doha, Qatar.

\begin{abstract}
Adoptive cell transfer (ACT) of purified naive, stem cell memory, and central memory T cell subsets results in superior persistence and antitumor immunity compared with ACT of populations containing more-differentiated effector memory and effector T cells. Despite a clear advantage of the less-differentiated populations, the majority of ACT trials utilize unfractionated T cell subsets. Here, we have challenged the notion that the mere presence of less-differentiated T cells in starting populations used to generate therapeutic T cells is sufficient to convey their desirable attributes. Using both mouse and human cells, we identified a T cell-T cell interaction whereby antigen-experienced subsets directly promote the phenotypic, functional, and metabolic differentiation of naive T cells. This process led to the loss of less-differentiated T cell subsets and resulted in impaired cellular persistence and tumor regression in mouse models following ACT. The T memoryinduced conversion of naive T cells was mediated by a nonapoptotic Fas signal, resulting in Akt-driven cellular differentiation. Thus, induction of Fas signaling enhanced T cell differentiation and impaired antitumor immunity, while Fas signaling blockade preserved the antitumor efficacy of naive cells within mixed populations. These findings reveal that $\mathrm{T}$ cell subsets can synchronize their differentiation state in a process similar to quorum sensing in unicellular organisms and suggest that disruption of this quorum-like behavior among T cells has potential to enhance T cell-based immunotherapies.
\end{abstract}

\section{Introduction}

Adoptive cell transfer (ACT), the ex vivo expansion and reinfusion of antigen-specific (Ag-specific) T cells, represents a potentially curative treatment for patients with advanced cancer (1-4) and viral-reactivation syndromes $(1,5,6)$. Recent progress in the ability to genetically redirect patient-derived peripheral blood $\mathrm{T}$ cells toward tumor and viral-associated antigens by modification with a $\mathrm{T}$ cell receptor (TCR) or chimeric antigen receptor (CAR) has greatly simplified the generation of therapeutic T cells (7-10). Given the clinical efficacy of T cell therapy combined with the ability of T cells to be manufactured according to standardized procedures, ACT is now poised to enter mainstream clinical practice. However, fundamental questions remain regarding the optimal source, expansion, and quality of therapeutic $\mathrm{T}$ cells used for transfer.

\section{Related Commentary: p. 35}

Authorship note: C.A. Klebanoff, C.D. Scott, and A.J. Leonardi are co-first authors Conflict of interest: The authors have declared that no conflict of interest exists. Submitted: February 4, 2015; Accepted: October 26, 2015.

Reference information: / Clin Invest. 2016;126(1):318-334. doi:10.1172/JCI81217.
In mice, ACT of naive $C D 8^{+} \mathrm{T}$ cell-derived cells $\left(\mathrm{T}_{\mathrm{N}}\right.$-derived cells) exhibits a superior capacity to expand, persist, and treat cancer compared with normalized numbers of memory $\mathrm{T}$ cellderived cells $\left(\mathrm{T}_{\text {Mem }}\right.$ cells) $(11,12)$. Preclinical human studies have confirmed that $\mathrm{T}_{\mathrm{N}}$-derived cells maintain higher levels of the costimulatory marker CD27 and the lymphoid homing markers CD62L and CCR7; they also retain longer telomeres (12-15). Each of these parameters has correlated with the likelihood that patients will obtain an objective clinical response following ACT (15-17). Despite these findings, the majority of current $\mathrm{T}$ cell therapy clinical trials do not specifically enrich for defined $\mathrm{T}$ cell subsets, but rather utilize unfractionated T cell populations (2). As $\mathrm{T}_{\mathrm{N}}$ cells are in the circulation of most cancer patients $(13,18)$, the following question arises: is the presence of $\mathrm{T}_{\mathrm{N}}$ cells in the initial population used to generate therapeutic $\mathrm{T}$ cells sufficient to convey their desirable attributes, or is physical separation of $\mathrm{T}_{\mathrm{N}}$ cells from antigen-experienced subsets required to unleash the full therapeutic potential of $\mathrm{T}_{\mathrm{N}}$-derived cells $(19,20)$ ? Prior investigations revealed that $\mathrm{T}_{\mathrm{N}}$ cells form homotypic clusters during $\mathrm{T}$ cell priming that can influence their subsequent maturation (21, 22). However, whether antigen-experienced populations directly interact with and influence naive cell differentiation is unknown. 
Using human and mouse $\mathrm{T}$ cells, we describe here a previously unrecognized $\mathrm{T}$ cell-T cell interaction whereby $\mathrm{T}_{\text {Mem }}$ cells directly influence $\mathrm{T}_{\mathrm{N}}$ cell differentiation during priming. This process, which we term precocious differentiation, synchronizes the behavior of $\mathrm{T}_{\mathrm{N}}$-derived cells with $\mathrm{T}_{\mathrm{Mem}}$ cells, resulting in accelerated functional, transcriptional, and metabolic differentiation of $\mathrm{T}_{\mathrm{N}}$ cell progeny. Precocious differentiation was cell-dose, contact, and activation dependent. Mechanistically, the phenomenon was mediated by nonapoptotic Fas signaling, resulting in activation of Akt and ribosomal S6 protein (S6), kinases responsible for cellular differentiation and metabolism (23). Consequently, induction of Fas signaling in the absence of $\mathrm{T}_{\mathrm{Mem}}$ cells enhanced differentiation and impaired antitumor immunity, while isolation of $\mathrm{T}_{\mathrm{N}}$ cells prior to priming or blockade of Fas signaling prevented $\mathrm{T}_{\mathrm{Mem}}$ cellinduced precocious differentiation and preserved the antitumor efficacy of $\mathrm{T}_{\mathrm{N}}$-derived cells. Collectively, our results reveal that unleashing the therapeutic potential of $\mathrm{T}_{\mathrm{N}}$-derived cells for adoptive immunotherapy necessitates disruption of intercellular communication with $\mathrm{T}_{\mathrm{Mem}}$ cells, a finding with direct implications for the design and execution of ACT clinical trials.

\section{Results}

$T_{\text {Mem }}$ augment naive cell phenotypic maturation during ex vivo priming. We sought to determine whether antigen-experienced $\mathrm{CD}^{+} \mathrm{T}$ cells influence the differentiation of $\mathrm{T}_{\mathrm{N}}$-derived progeny. To indelibly track the fate of $\mathrm{T}_{\mathrm{N}}$ cells, we primed congenically distinguishable Thy1.1 $1^{+}$pmel-1 CD ${ }^{+} \mathrm{T}_{\mathrm{N}}$ cells $\left(\mathrm{CD} 44^{\mathrm{lo}} \mathrm{CD} 62 \mathrm{~L}^{+}\right)$, which recognize an epitope derived from the melanoma-associated Ag gp100 (24), alone or in a 1:1 mixture with Ly5.1 $1^{+} \mathrm{T}_{\text {Mem }}$ cells. To generate $\mathrm{T}_{\text {Mem }}$ cells, we adoptively transferred Ly5.1+ pmel-1 T cells into WT Ly5.2 $2^{+}$hosts and vaccinated recipient mice with a gp100-encoding recombinant vaccinia virus (rVV-gp100) to generate Ag-experienced $\mathrm{CD}^{+} \mathrm{T}$ cells in vivo. Twenty-eight days later, Ly5.1 ${ }^{+} \mathrm{CD} 8^{+}$ $\mathrm{T}$ central memory cell $\left(\mathrm{T}_{\mathrm{CM}}\right.$ cell; CD $\left.44^{\text {hi }} \mathrm{CD} 62 \mathrm{~L}^{+}\right)$and $\mathrm{T}$ effector memory cell $\left(\mathrm{T}_{\mathrm{EM}}\right.$ cell; CD $\left.44^{\text {hi }} \mathrm{CD} 62 \mathrm{~L}^{-}\right)$subsets from vaccinated mice were isolated by FACS sorting (Figure 1A). Naive pmel-1 cells were subsequently expanded alone or in the presence of $\mathrm{T}_{\mathrm{CM}}$ or $\mathrm{T}_{\mathrm{EM}}$ cells using anti-CD3/CD28 antibodies and IL-2, which is similar to many current human ACT protocols $(15,25,26)$.

Following expansion, the progeny of isolated $\mathrm{T}_{\mathrm{N}}$ cells had differentiated into all 3 antigen-experienced subsets, including $\mathrm{T}$ stem cell memory cells $\left(\mathrm{T}_{\mathrm{SCM}}\right.$ cells; CD $\left.44^{\mathrm{lo}} \mathrm{CD} 62 \mathrm{~L}^{+} \mathrm{CD} 122^{+} \mathrm{Sca}-1^{+}\right)$, $\mathrm{T}_{\mathrm{CM}}$ cells, and $\mathrm{T}_{\mathrm{EM}}$ cells (refs. 27, 28, Figure 1B, and Supplemental Figure 1; supplemental material available online with this article; doi:10.1172/JCI81217DS1). Strikingly, we found that the presence of $\mathrm{T}_{\mathrm{Mem}}$ cells during $\mathrm{T}_{\mathrm{N}}$ cell priming caused a significant accumulation of $\mathrm{T}_{\mathrm{EM}}$ cells and an attrition of $\mathrm{T}_{\mathrm{SCM}}$ cells (Figure 1C). Both $\mathrm{T}_{\mathrm{CM}}$ and $\mathrm{T}_{\mathrm{EM}}$ cell subsets were equally capable of augmenting the phenotypic maturation of $\mathrm{T}_{\mathrm{N}}$-derived progeny, demonstrating that this prodifferentiation capacity was a property of $\mathrm{T}_{\mathrm{Mem}}$ cell subsets in general. These findings were not attributable to differences in cell expansion, were not TCR specific, and occurred regardless of growth and cytokine conditions tested (Supplemental Figures 2 and 3). Augmented $\mathrm{T}_{\mathrm{N}}$ cell differentiation was also observed when a CD4-containing bulk $\mathrm{T}_{\mathrm{Mem}}$ cell population was used, although the magnitude of change was less than that observed using CD8 ${ }^{+}$ $\mathrm{T}_{\mathrm{Mem}}$ cells (Supplemental Figure 4).
As the frequency of circulating $\mathrm{T}_{\text {Mem }}$ cells to $\mathrm{T}_{\mathrm{N}}$ cells can vary widely in patients $(18,29,30)$, we evaluated the dose dependency of $\mathrm{T}_{\mathrm{Mem}}$ cell-induced phenotypic maturation of $\mathrm{T}_{\mathrm{N}}$ cells. We activated $\mathrm{T}_{\mathrm{N}}$ cells alone or in titrated ratios with a bulk $\left(\mathrm{CD} 44^{+}\right) \mathrm{T}_{\mathrm{Mem}}$ cell population. Similar to results using fractionated $\mathrm{T}_{\mathrm{CM}}$ and $\mathrm{T}_{\mathrm{EM}}$ cell subsets, we found that priming $\mathrm{T}_{\mathrm{N}}$ cells in a 1:1 mixture with bulk $\mathrm{T}_{\mathrm{Mem}}$ cells caused an increase in the $\mathrm{T}_{\mathrm{EM}}$ cell population and a corresponding loss in $\mathrm{T}_{\mathrm{SCM}}$ and $\mathrm{T}_{\mathrm{CM}}$ cells (Figure $1, \mathrm{D}$ and $\mathrm{E}$ ). As the ratio of $\mathrm{T}_{\mathrm{Mem}}$ to $\mathrm{T}_{\mathrm{N}}$ cells was increased, we measured a progressive enhancement in the differentiation of $\mathrm{T}_{\mathrm{N}}$-derived progeny. We conclude that the presence of $\mathrm{T}_{\mathrm{Mem}}$ cells during $\mathrm{T}_{\mathrm{N}}$ cell priming ex vivo caused dose-dependent phenotypic maturation of $\mathrm{T}_{\mathrm{N}}$-derived cells.

$T_{\text {Mem }}$ cause precocious differentiation of naive cells. Having established that $\mathrm{T}_{\mathrm{Mem}}$ cells augment the phenotypic maturation of $\mathrm{T}_{\mathrm{N}}$ cells during priming, we next evaluated whether $\mathrm{T}_{\mathrm{Mem}}$ cells influence gene transcription and effector functions of $\mathrm{T}_{\mathrm{N}}$-derived progeny. We again primed Ly5.1 $1^{+} \mathrm{T}_{\mathrm{N}}$ pmel-1 cells alone or in a 1:1 ratio with bulk in vitro-differentiated Ly5.2 ${ }^{+} \mathrm{T}_{\text {Mem }}$ cells and confirmed that the progeny of $\mathrm{T}_{\mathrm{N}}$ cells expanded with $\mathrm{T}_{\mathrm{Mem}}$ cells $\left(\mathrm{T}_{\mathrm{N}}\right.$-derived, mix) were significantly skewed toward $\mathrm{T}_{\mathrm{EM}}$ cells and away from $\mathrm{T}_{\mathrm{SCM}}$ cells compared with $\mathrm{T}_{\mathrm{N}}$ cells primed alone $\left(\mathrm{T}_{\mathrm{N}}{ }^{-}\right.$ derived, alone) (Figure 2, A and B). To determine whether CD62L loss on $\mathrm{T}_{\mathrm{N}}$-derived cells was attributable to genetic downregulation rather than proteolytic cleavage, we reisolated Ly5.1+ $\mathrm{T}_{\mathrm{N}}{ }^{-}$ derived cells following expansion by FACS sorting and performed quantitative PCR (qPCR). We found that expression of selectin $\mathrm{L}$ $(\mathrm{Sell})$, the gene encoding CD62L as well as other $\mathrm{T}_{\mathrm{N}}$ cell-associated lymphoid-homing and costimulatory markers, including $\mathrm{Ccr} 7$ and $C d 27$, was significantly downregulated in $\mathrm{T}_{\mathrm{N}}$-derived cells expanded with $\mathrm{T}_{\mathrm{Mem}}$ cells relative to $\mathrm{T}_{\mathrm{N}}$ cells expanded alone (Figure $2 \mathrm{C}$ ). Additionally, we found that $\mathrm{T}_{\mathrm{N}}$-derived cells primed with $\mathrm{T}_{\text {Mem }}$ cells were more functionally differentiated, as evidenced by increased granzyme B content (Figure 2D) and enhanced IFN- $\gamma$ secretion following stimulation with either PMA/ionomycin or hpg100 ${ }_{25-33}$ peptide (Figure 2, E and F).

To globally assess the influence of $\mathrm{T}_{\mathrm{Mem}}$ cells on the differentiation of $\mathrm{T}_{\mathrm{N}}$-derived progeny, we performed gene-expression analyses of reisolated cells at rest and at serial time points following activation. Hierarchical clustering demonstrated that within 18 hours, $\mathrm{T}_{\mathrm{N}}$ cells primed with $\mathrm{T}_{\mathrm{Mem}}$ cells had a gene-expression profile more closely related to $\mathrm{T}_{\mathrm{Mem}}$ cells than to $\mathrm{T}_{\mathrm{N}}$ cells (Figure $2 \mathrm{G}$ ). We found that 139 and 259 transcripts were differentially expressed (fold change $[\mathrm{FC}]>2$, positive FDR $[\mathrm{pFDR}]<0.05$ ) between $\mathrm{T}_{\mathrm{N}}$ cells primed alone or with $\mathrm{T}_{\mathrm{Mem}}$ cells at 18 hours and 96 hours, respectively (Supplemental Tables 1 and 2). In contrast, only 0 and 10 transcripts were differentially expressed by these criteria in $\mathrm{T}_{\mathrm{Mem}}$ cells expanded alone or with $\mathrm{T}_{\mathrm{N}}$ cells at these time points (Supplemental Table 3), indicating that the predominant outcome of this $\mathrm{T}$ cell-T cell interaction was $\mathrm{T}_{\mathrm{Mem}}$ cell-induced changes in $\mathrm{T}_{\mathrm{N}}$ cells. Examination of specific genes revealed that key naive and memory-associated transcription factors (TFs), including transcription factor 7 (Tcf7) (27), Kruppel-like factor 2 (Klf2) (31), and forkhead box $\mathrm{O} 1$ (Foxo1) (32), were significantly downregulated in $\mathrm{T}_{\mathrm{N}}$ cells primed with $\mathrm{T}_{\text {Mem }}$ cells compared with $\mathrm{T}_{\mathrm{N}}$ cells primed alone (Figure $2 \mathrm{H}$ ). Conversely, genes encoding effector-associated TFs and molecules, such as T-box 21 (Tbx21) (33), PR domain containing 1, 
A

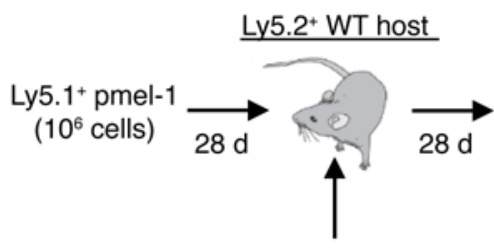

Vaccinate with rVV-gp100 ( $\left.2 \times 10^{7} \mathrm{pfu}\right)$
Ly5.1+ CD8+-gated:

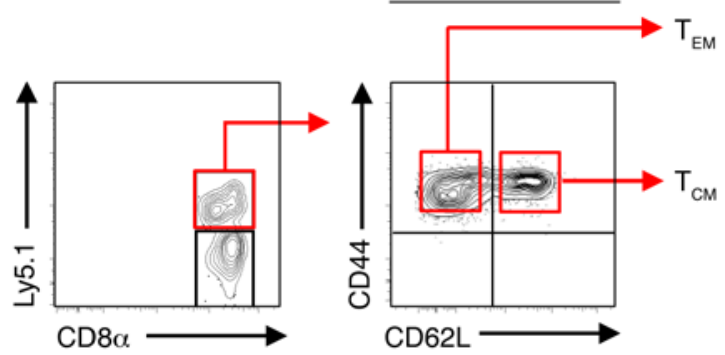

B

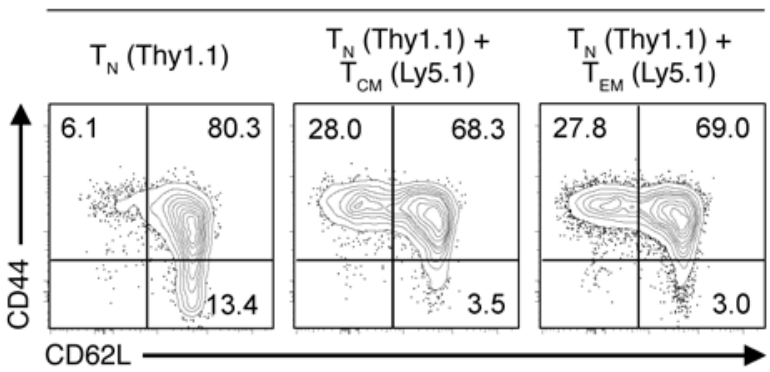

Thy1.1+ CD8+-gated:

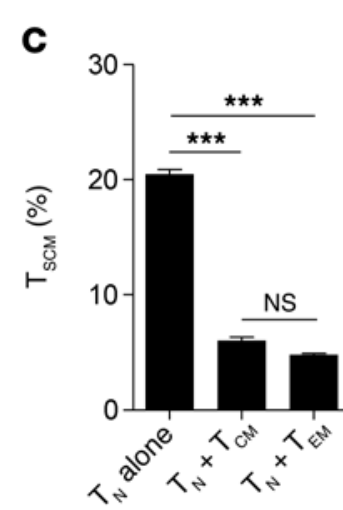

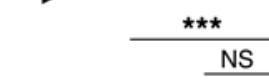

NS

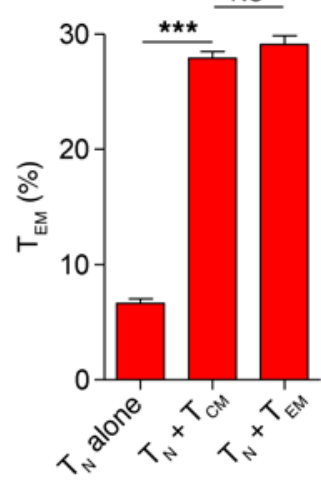

D

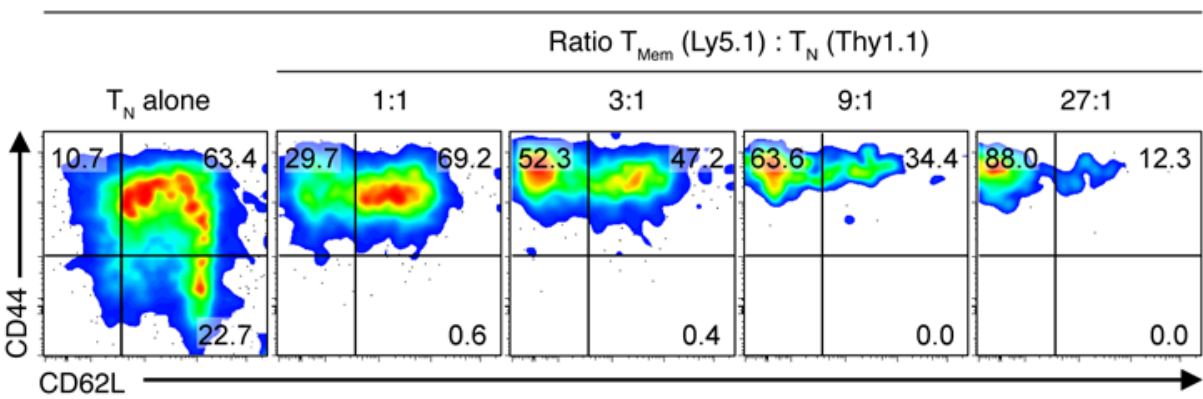

E

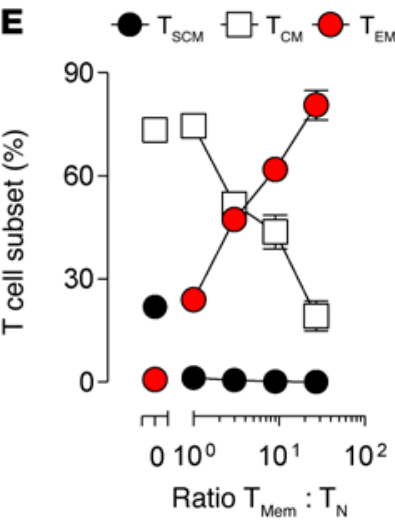

Figure 1. $\mathbf{T}_{\text {Mem }}$ cells augment naive cell phenotypic maturation during priming. (A) Experimental design and representative FACS plot showing the generation and isolation of vaccine-induced pmel-1 Ly5.1 $1^{+} \mathrm{CD}^{+} \mathrm{T}_{\mathrm{CM}}\left(\mathrm{CD} 44^{+} \mathrm{CD} 62 \mathrm{~L}^{+}\right)$and $\mathrm{T}_{\mathrm{EM}}\left(\mathrm{CD} 44^{+} \mathrm{CD} 62 \mathrm{~L}^{-}\right)$cell subsets by adoptive transfer of pmel-1 cells (10 $)$into Ly5.2+ WT hosts followed by rVV-gp100 vaccination $\left(2 \times 10^{7} \mathrm{pfu}\right)$. (B) Representative FACS plots and (C) summary bar graphs demonstrating the distribution of Thy1.1 $1^{+} \mathrm{T}_{\mathrm{N}}$-derived $\mathrm{T}_{\mathrm{SCM}}\left(\mathrm{CD} 44^{\mathrm{l}}{ }^{\circ} \mathrm{CD} 62 \mathrm{~L}^{+} \mathrm{SCa} 1^{+} \mathrm{CD} 122^{+}\right)$and $\mathrm{T}_{\mathrm{EM}}$ cell subsets 6 days following ex vivo expansion alone or in the presence of a 1:1 mixture with Ly5.2 $2^{+} T_{C M}$ or $T_{E M}$ cells using CD3/CD28-specific antibodies and IL-2. (D) Representative FACS plots and (E) summary graph demonstrating the distribution of Thy $1.1^{+} T_{N}$-derived subsets 6 days following ex vivo expansion alone or in the presence of titrated ratios with Ly5.1+ bulk (CD44+) $T_{\text {Mem }}$ cells using CD3/CD28-specific antibodies and IL-2. Results in A-E are shown after gating on live ${ }^{+}$CD8 ${ }^{+}$Thy1.1 $1^{+}$Iymphocytes and are representative of 2 independently performed experiments. Results in $\mathbf{C}$ and $\mathbf{E}$ are presented as mean \pm SEM with $n=3$ per condition. Statistical comparisons performed using an unpaired 2-tailed Student's $t$ test corrected for multiple comparisons by a Bonferroni adjustment. ${ }^{* * *} P<0.001$.

with ZNF domain (Prdm1) (34), and granzyme B (Gzmb) were differentially overexpressed in $\mathrm{T}_{\mathrm{N}}$ cells primed with $\mathrm{T}_{\mathrm{Mem}}$ cells (Figure 2I). Collectively, these data revealed that $\mathrm{T}_{\text {Mem }}$ cells globally altered the differentiation program of $\mathrm{T}_{\mathrm{N}}$ cells.

Finally, to assess the impact of $\mathrm{T}_{\mathrm{Mem}}$ cell-induced differentiation of $\mathrm{T}_{\mathrm{N}}$-derived cells on antitumor efficacy, we adoptively transferred $\mathrm{T}_{\mathrm{N}}$ cells primed alone or with $\mathrm{T}_{\text {Mem }}$ cells into mice bearing 10-day established s.c. B16 melanomas. We found that the expansion, persistence, and antitumor efficacy of $\mathrm{T}_{\mathrm{N}}$-derived cells were all significantly impaired in mice receiving $\mathrm{T}_{\mathrm{N}}$-derived cells primed with $\mathrm{T}_{\mathrm{Mem}}$ cells compared with $\mathrm{T}_{\mathrm{N}}$-derived cells primed alone $(P=0.009)$ (Figure 2, J and $\mathrm{K}$ ). We conclude that the presence of $\mathrm{T}_{\mathrm{Mem}}$ cells dur- ing $\mathrm{T}_{\mathrm{N}}$ cell priming ex vivo caused enhanced phenotypic, functional, and transcriptional differentiation of $\mathrm{T}_{\mathrm{N}}$-derived cells relative to $\mathrm{T}_{\mathrm{N}}$ cells primed alone, resulting in impaired antitumor efficacy. Henceforth, we will refer to this process as precocious differentiation.

$T_{\text {Mem }}$ cells cause precocious differentiation of $T_{N}$ cells in vivo. Having established that $\mathrm{T}_{\mathrm{Mem}}$ augment naive cell differentiation during ex vivo expansion, we next asked whether $\mathrm{T}_{\mathrm{Mem}}$ cells also influence $\mathrm{T}_{\mathrm{N}}$ cell differentiation and antitumor efficacy in vivo after adoptive cotransfer. In prior studies, naive cell expansion and differentiation were impaired when limited numbers $\left(5 \times 10^{2}\right)$ of $\mathrm{T}_{\mathrm{N}}$ cells were transferred into hosts containing a 100- to 1,000-fold greater frequency of $\mathrm{T}_{\mathrm{Mem}}$ cells (35). Under these conditions, $\mathrm{T}_{\mathrm{N}}$ cells are 
A

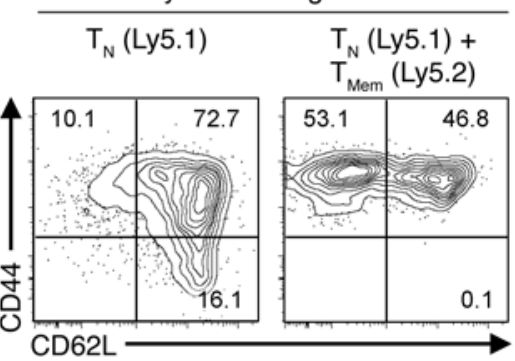

D

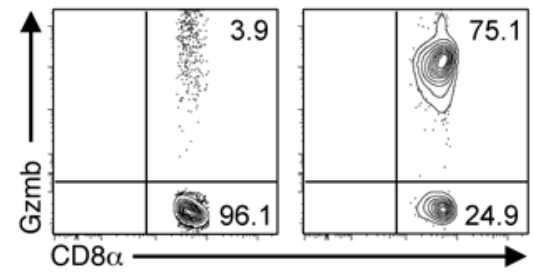

E

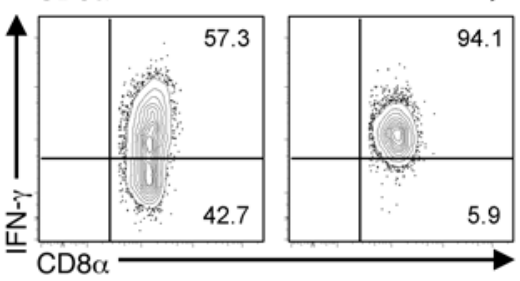

H

- $\mathrm{T}_{\mathrm{N}}$-derived, alone $\bullet \mathrm{T}_{\mathrm{N}}$-derived, mix $\square \mathrm{T}_{\text {Mem }}$-derived, alone

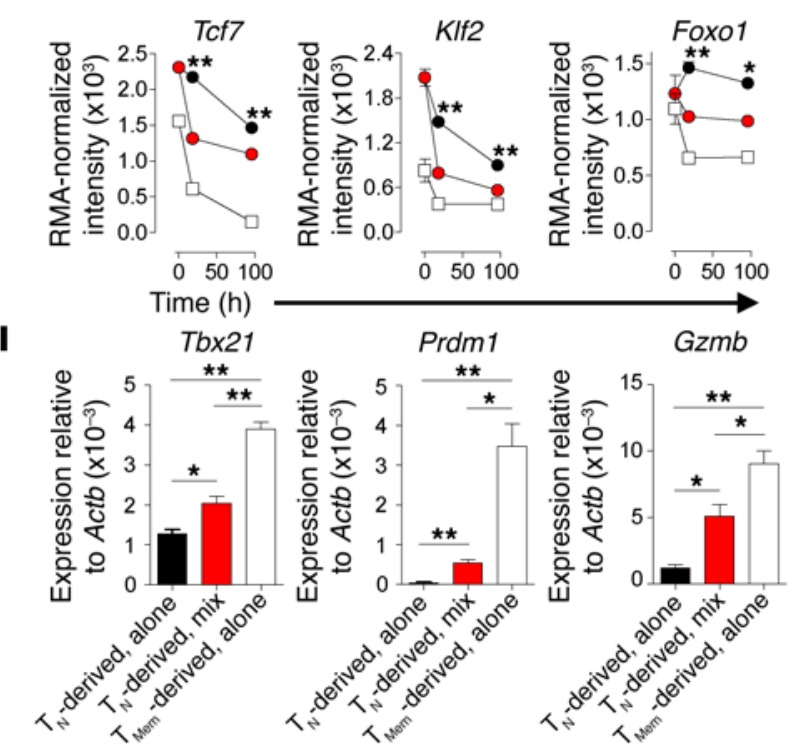

C

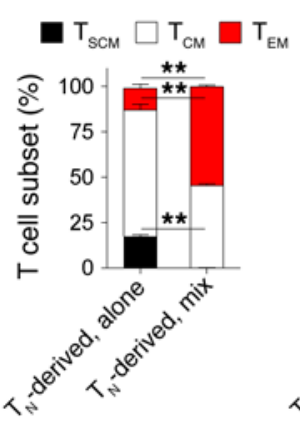

F $\mathrm{T}_{\mathrm{N}}$-derived, alone - $T_{N}$-derived, mix

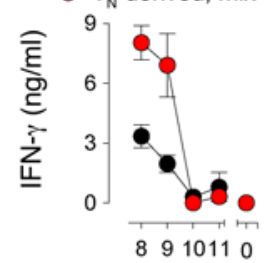

$-\log \left[\mathrm{hgp} 100_{25-33}\right] \mathrm{M}$
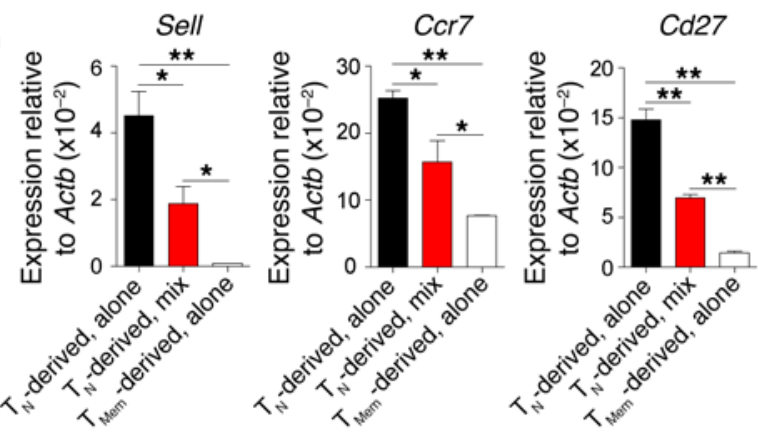

G

$T_{N}$-derived, alone

$\mathrm{T}_{\mathrm{N}}$-derived, mix

$18 \mathrm{~h}$

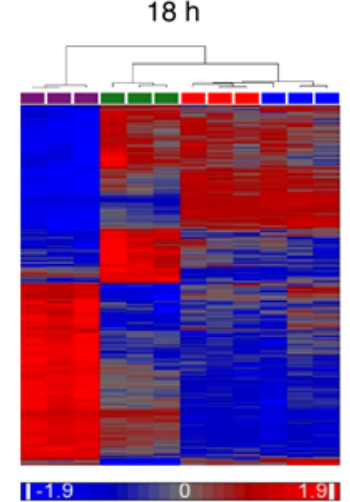

J $\bullet \mathrm{T}_{\mathrm{N}}$-derived, alone

- $T_{N}$-derived, mix

$\square \mathrm{T}_{\text {Mem }}$-derived, alone

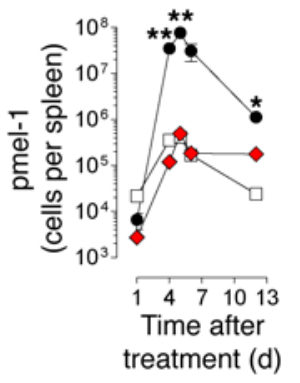

$\mathbf{K}$

$T_{\text {Mem }}$-derived, alone

$\mathrm{T}_{\text {Mem }}$-derived, mix

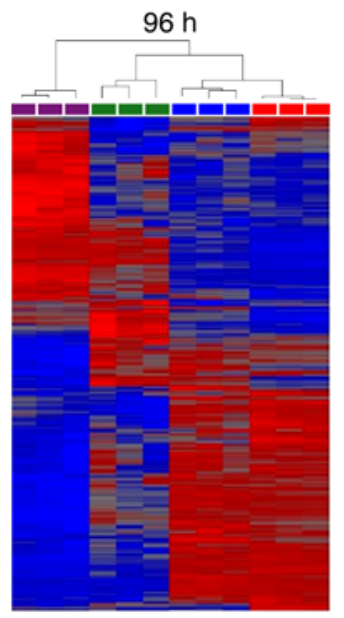

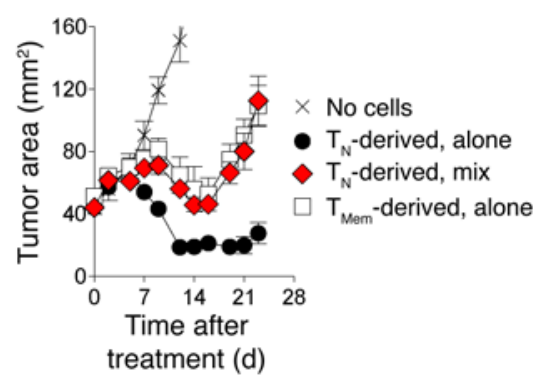

Figure 2. $T_{\text {Mem }}$ cause precocious differentiation of naive cells. (A) Representative FACS and (B) bar graph summarizing the distribution of Ly5.1+CD8 ${ }^{+}$ $T_{N}$-derived cell subsets 6 days following priming with CD3/CD28-specific antibodies and IL-2 alone or with Ly5.2 $2^{+}$CD8 ${ }^{+} T_{\text {Mem }}$ cells. Data shown after gating on Ly5.1+CD8 ${ }^{+}$cells. (C) qPCR analysis of Sell, CCr7, and Cd27 expression in FACS-sorted reisolated $\mathrm{T}_{\mathrm{N}}$ cells primed alone, $\mathrm{T}_{\mathrm{N}}$ cells primed with $\mathrm{T}_{\text {Mem }}$ cells, or $\mathrm{T}_{\text {Mem }}$ cells primed alone. (D) Granzyme B and (E) IFN- $\gamma$ intracellular staining in $\mathrm{T}_{\mathrm{N}}$-derived cells stimulated with PMA/ionomycin following expansion alone or with $\mathrm{T}_{\text {Mem }}$ cells. (F) IFN- $\gamma$ ELISA of supernatants from reisolated $\mathrm{T}_{\mathrm{N}}$-derived cells expanded alone or with $\mathrm{T}_{\text {Mem }}$ cells 6 days prior to overnight stimulation with hgp100 ${ }_{25-33}$ peptide. (G) Heat maps of differentially expressed genes (1-way ANOVA, pFDR < $\%$ ) among $\mathrm{T}_{\mathrm{N}}$-derived cells expanded alone or with $\mathrm{T}_{\text {Mem }}$ cells at 18 and 96 hours. (H) RMA-normalized intensity of selected $\mathrm{T}_{\mathrm{N}}$-associated genes. (I) Expression of effector cell-associated factors assessed by qPCR at 96 hours from FACS reisolated $T_{N}$-derived progeny expanded with or without $T_{M e m}$ cells or $T_{M e m}$ cells expanded alone. (J) In vivo expansion and (K) tumor regression following i.v. adoptive transfer of $\mathrm{T}_{\mathrm{N}}$-derived progeny expanded alone or with $\mathrm{T}_{\mathrm{Mem}}$ cells, or $\mathrm{T}_{\text {Mem }}$ cells grown alone in combination with 6 Gy irradiation, i.v. rVV-hgp100, and 3 days of i.p. IL-2. $n=3$ independently maintained cultures/condition or time point for experiments shown in B, C, and F-I. K was performed with $n=5$ mice per group. All results shown as mean \pm SEM. Statistical comparisons performed using an unpaired 2-tailed Student's $t$ test corrected for multiple comparisons by Bonferroni adjustment. ${ }^{*} P<0.05 ;{ }^{*} P<0.01$. Data are representative of 16 (A and $\left.\mathbf{B}\right), 3$ (D and $\left.\mathbf{E}\right)$, and 2 (C, $\mathbf{F}$, and $\mathbf{I}-\mathbf{K})$ independent experiments. 
A

pmel-1 Ly5.1+ host

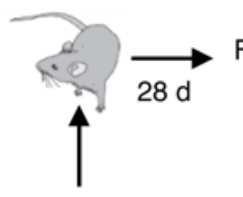

rVV-gp100

( $\left.2 \times 10^{7} \mathrm{pfu}\right)$

pmel-1 Thy $1.1^{+}$host

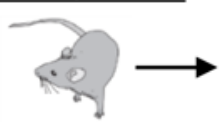

FACS sort $\mathrm{T}_{\mathrm{N}}$ $\left(\mathrm{CD} 44^{10} \mathrm{CD} 62 \mathrm{~L}^{+}\right)$
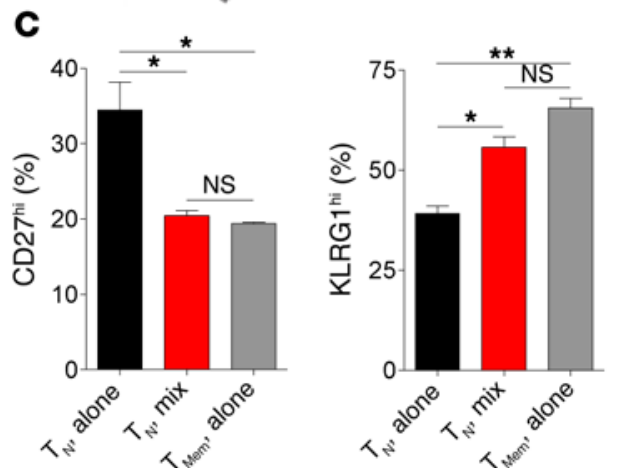

B
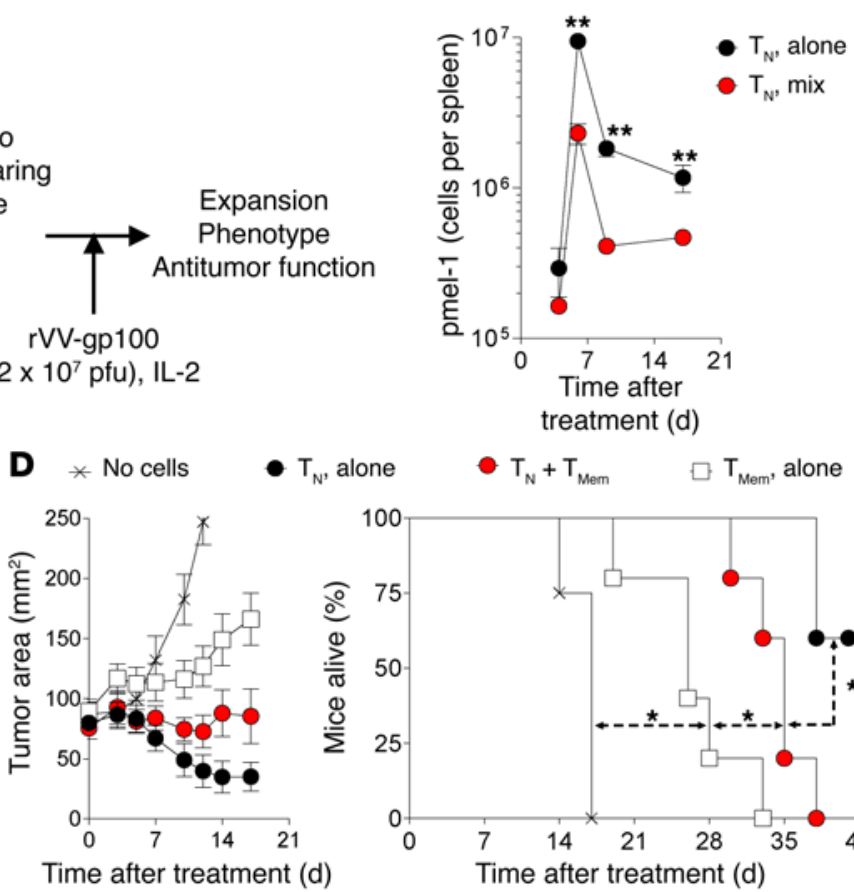

rVV-gp100

( $\left.2 \times 10^{7} \mathrm{pfu}\right), \mathrm{IL}-2$

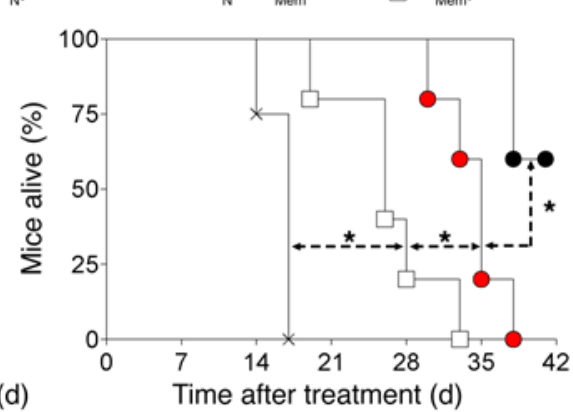

Transfer into

B16 tumor-bearing

Ly5.2+ mice

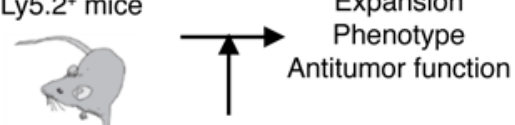

Figure 3. $\mathbf{T}_{\mathrm{Mem}}$ cells cause precocious differentiation of $\mathbf{T}_{\mathrm{N}}$ cells in vivo. (A) Experimental schema showing the generation, isolation, and transfer of Thy1.1 $1^{+}$

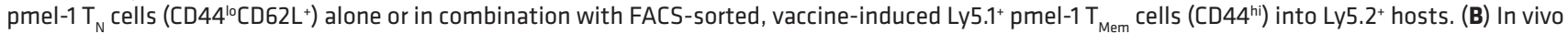

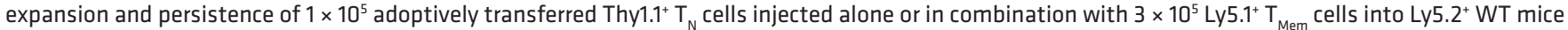

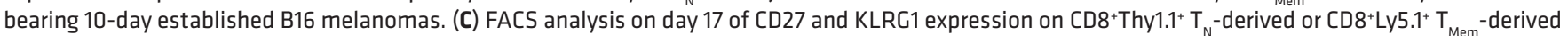
cells. (D) Tumor regression and survival of mice bearing 10-day established B16 melanoma tumors who received $1 \times 10^{5} \mathrm{~T}_{\mathrm{N}}$ cells alone, in combination with $3 \times 10^{5} \mathrm{~T}_{\mathrm{Mem}}$ cells, or $3 \times 10^{5} \mathrm{~T}_{\mathrm{mem}}$ cells alone. All treated mice received 6 Gy irradiation, i.v. rVV-gp100, and 3 days of i.p. IL-2. $n=3$ mice/group/time point (B and $\mathbf{C}$ ) or $n=5$ mice per group (D). Results are displayed as mean \pm SEM with statistical comparisons performed using an unpaired 2-tailed Student's $t$ test corrected for multiple comparisons by a Bonferroni adjustment or log-rank test for animal survival. ${ }^{*} P<0.05 ;{ }^{* *} P<0.01$. Data shown are representative of 2 independently performed experiments.

numerically outcompeted by $\mathrm{T}_{\mathrm{Mem}}$ cells for limited antigen presented by professional antigen-presenting cells, thereby limiting their priming and differentiation (36). However, whether $\mathrm{T}_{\mathrm{N}}$ cell differentiation and antitumor efficacy is influenced when large numbers of cells typically used in adoptive immunotherapies are cotransferred in conjunction with $\mathrm{T}_{\mathrm{Mem}}$ cells has not been previously evaluated. Therefore, we adoptively transferred $\left(1 \times 10^{5}\right)$ Thy $1.1^{+} \mathrm{T}_{\mathrm{N}}$ pmel-1 cells alone or in combination with $\left(3 \times 10^{5}\right)$ FACS-sorted, vaccineinduced, Ly5.1 $1^{+}$pmel-1 $\mathrm{T}_{\mathrm{Mem}}$ cells into sublethally irradiated Ly5.2 $2^{+}$ hosts bearing 10-day established B16 melanoma tumors (Figure 3A). In addition to cells, recipient mice also received rVV-gp100 vaccination and exogenous IL-2. We found that both the expansion and persistence of $\mathrm{T}_{\mathrm{N}}$ cell-derived progeny were significantly impaired when cotransferred with $\mathrm{T}_{\mathrm{Mem}}$ cells (Figure 3B). In contrast, the recall response of cotransferred $\mathrm{T}_{\mathrm{Mem}}$ cells was not affected compared with $\mathrm{T}_{\mathrm{Mem}}$ cells transferred alone (Supplemental Figure 5). These findings were not due to a failure of $T_{N}$ cells to become primed in vivo, as a significantly larger proportion of the $\mathrm{T}_{\mathrm{N}}$-derived population cotransferred with $\mathrm{T}_{\mathrm{Mem}}$ cells lost $\mathrm{CD} 27$ expression and acquired the senescent marker killer cell lectin-like receptor subfamily G1 (KLRG1) at the conclusion of the immune response compared with $\mathrm{T}_{\mathrm{N}}$ cells transferred alone (Figure 3C). Importantly, both tumor regression and animal survival were significantly impaired $(P<0.05)$ in mice receiving $\mathrm{T}_{\mathrm{N}}$ cells and $\mathrm{T}_{\mathrm{Mem}}$ cells together com- pared with $\mathrm{T}_{\mathrm{N}}$ cells alone (Figure 3D). We conclude that $\mathrm{T}_{\mathrm{Mem}}$ cells can cause precocious differentiation and impaired antitumor efficacy of $\mathrm{T}_{\mathrm{N}}$ cell-derived progeny in vivo following adoptive cotransfer.

FasL-Fas interactions mediate precocious differentiation. We next sought to elucidate what $\mathrm{T}_{\mathrm{Mem}}$ cell factor or factors caused precocious differentiation. We determined the phenomenon was, in addition to being cell-dose dependent, also cell-contact dependent and activation dependent and could not be reproduced using supernatant transfers from restimulated $\mathrm{T}_{\mathrm{Mem}}$ cells (Supplemental Figure 6). Accordingly, we hypothesized that an activationinduced, cell-surface molecule on $\mathrm{T}_{\mathrm{Mem}}$ cells that can mediate costimulatory-like effects was responsible. Several members of the TNF superfamily satisfy these criteria (37). Therefore, we interrogated our microarray analysis comparing gene expression in $\mathrm{T}_{\mathrm{Mem}}$ cells and $\mathrm{T}_{\mathrm{N}}$ cells for TNF superfamily members uniquely overexpressed in activated $\mathrm{T}_{\mathrm{Mem}}$ cells to generate a list of candidate ligands. Among the 19 known TNF superfamily ligands (37), only Fasl met criteria $\left(\log _{2} \mathrm{FC}>2, P<0.01\right)$ for being differentially expressed in restimulated $\mathrm{T}_{\text {Mem }}$ cells (Figure $4 \mathrm{~A}$ and Supplemental Table 4). To determine whether $\mathrm{T}_{\mathrm{CM}}$ and $\mathrm{T}_{\mathrm{EM}}$ cells are similarly poised to express FasL following activation, we performed ChIPseq analysis to assess histone $\mathrm{H} 3$ methylation dynamics at the Fasl locus within resting $\mathrm{T}_{\mathrm{N}}, \mathrm{T}_{\mathrm{CM}}$, and $\mathrm{T}_{\mathrm{EM}}$ cell subsets. Consistent with previous reports (38), we found that $\mathrm{T}_{\mathrm{N}}$ cells exhibited strong depo- 
A

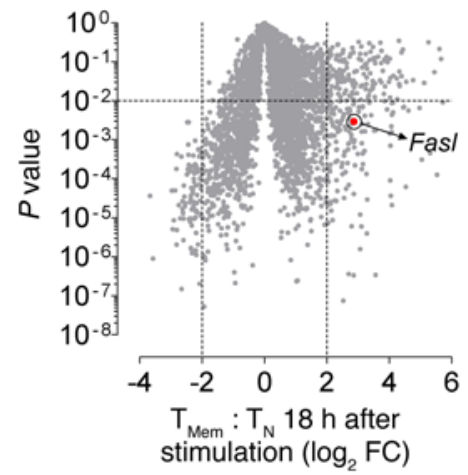

D

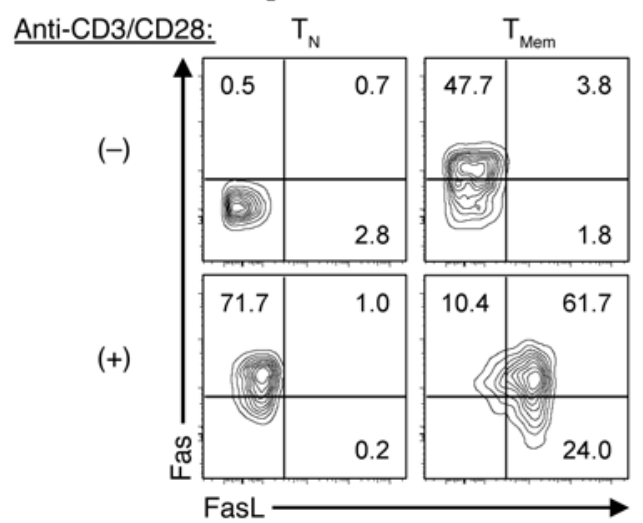

B

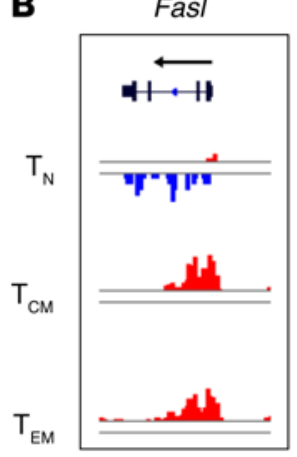

C

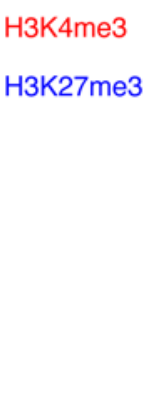

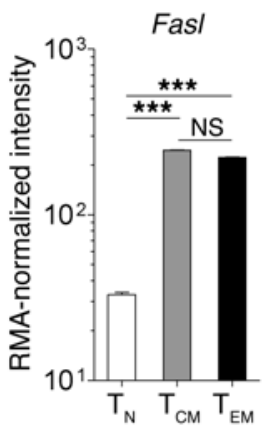

E

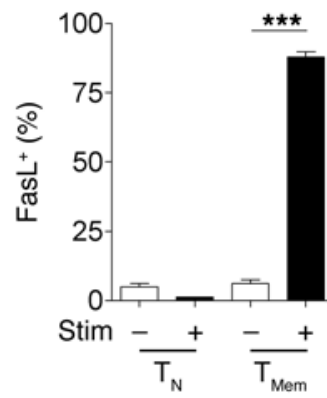

Figure 4. FasL is poised for rapid surface expression in $T_{\text {Mem }}$ cell subsets but not $T_{N}$ cells. (A) Volcano plot indicating differentially expressed genes in $T_{\text {Mem }}$ cells versus $T_{N}$ cells 18 hours after stimulation with CD3/CD28specific antibodies and IL-2. Dashed lines, $P<0.01$ and $F C>2$. (B) Pattern of activating $\mathrm{H} 3 \mathrm{~K} 4 \mathrm{me} 3$ and repressive H3K27me3 epigenetic marks within the promoter and gene body of Fasl and (C) RMA-normalized expression intensity of Fas/ in resting FACS-sorted $T_{N}, T_{C M}$, and $T_{E M}$ cell subsets. ( $D$ and E) Fas and FasL surface expression on $\mathrm{T}_{\mathrm{N}}$ and $\mathrm{T}_{\mathrm{Mem}}$ cells at rest or 18 hours after stimulation with CD3/CD28specific antibodies. All bar graphs shown as mean \pm SEM with $n=3$ per indicated cell type or condition. Statistical comparisons performed using an unpaired 2-tailed Student's $t$ test corrected for multiple comparisons by a Bonferroni adjustment. ${ }^{* *} P<0.001$. Data shown in C-E are representative of 2 independently performed experiments. sition of the repressive epigenetic modification trimethylation of histone 3 at lysine 27 (H3K27me3) and minimal deposition of the activating $\mathrm{H} 3 \mathrm{~K} 4 \mathrm{me} 3$ mark (Figure $4 \mathrm{~B}$ ). In contrast, both $\mathrm{T}_{\mathrm{CM}}$ and $\mathrm{T}_{\mathrm{EM}}$ cells acquired permissive $\mathrm{H} 3 \mathrm{~K} 4 \mathrm{me} 3$ marks and lost all detectable H3K27me3 repressive marks. Correlated with these changes, mRNA expression of Fasl was significantly increased in contemporaneously evaluated $\mathrm{T}_{\mathrm{CM}}$ and $\mathrm{T}_{\mathrm{EM}}$ cells compared with $\mathrm{T}_{\mathrm{N}}$ cells (Figure 4C). Notably, there were no significant differences in Fasl gene expression between $\mathrm{T}_{\mathrm{CM}}$ and $\mathrm{T}_{\mathrm{EM}}$ cell subsets. We confirmed that $\mathrm{T}_{\mathrm{Mem}}$ cells but not $\mathrm{T}_{\mathrm{N}}$ cells are poised to express surface FasL at a protein level by performing FACS analysis for this molecule and its corresponding receptor, Fas, on both cell types at rest and 18 hours after activation (Figure 4, D and E).

FasL-Fas interactions can induce apoptosis through Fas-mediated activation of caspase-8 (39). However, Fas signaling can also perform nonapoptotic functions in a variety of tissues, including promotion of $\mathrm{T}$ cell costimulation (40), hepatocyte regeneration (41), tumor growth and invasiveness (42), and neuronal differentiation (43). To determine whether FasL can mediate precocious differentiation, we primed Ly5.1 ${ }^{+} \mathrm{T}_{\mathrm{N}}$ cells alone or in a 1:1 mixture with Ly5.2 $2^{+} \mathrm{T}_{\mathrm{Mem}}$ cells in the presence of a blocking antibody against FasL ( $\alpha$ FasL) or isotype control (IgG) and measured changes in $\mathrm{T}$ cell differentiation. Provision of $\alpha$ FasL during $\mathrm{T}_{\mathrm{N}}$ cell priming with $\mathrm{T}_{\mathrm{Mem}}$ cells significantly but incompletely limited precocious differentiation (Figure $5, \mathrm{~A}-\mathrm{C}$ ). Consistent with FACS data demonstrating a paucity of FasL expression on recently activated $\mathrm{T}_{\mathrm{N}}$ cells, we found no significant differences in the composition of $T_{N}$ cell-derived progeny when isolated naive cells were primed with $\alpha$ FasL compared with IgG (Supplemental Figure 7).
As antibody blockade may be incomplete, we complimented these findings by genetic means using $\mathrm{CD}^{+} \mathrm{T}_{\mathrm{N}}$ cells derived from Fasdeficient $l p r$ mice (44). Whereas $\mathrm{WT} \mathrm{T}_{\mathrm{N}}$ cells underwent augmented differentiation when primed with $\mathrm{T}_{\mathrm{Mem}}$ cells, $\mathrm{T}_{\mathrm{N}}$ cells from $l p r$ mice were completely protected from this phenomenon (Figure 5 , $\mathrm{D}$ and $\mathrm{E}$ ). We conclude that precocious differentiation results from a contact-dependent interaction in which $\mathrm{T}_{\mathrm{Mem}}$ cell-provided FasL engages Fas expressed on $\mathrm{T}_{\mathrm{N}}$ cells.

Nonapoptotic Fas signaling mediates precocious differentiation. To evaluate whether FasL-delivered signals were sufficient to induce precocious differentiation, we primed $T_{N}$ cells in the absence of $\mathrm{T}_{\mathrm{Mem}}$ cells with titrated amounts of recombinant FasL oligomerized through a leucine zipper domain (lz-FasL) (45). We found that lz-FasL caused a dose-dependent increase in the differentiation of $\mathrm{T}_{\mathrm{N}}$ cell-derived progeny, as evidenced by an increased frequency of $\mathrm{T}_{\mathrm{EM}}$ cells and enhanced IFN- $\gamma$ release upon restimulation (Figure 6, A and B). Moreover, we observed commensurate changes in the expression of key differentiation-associated genes, including Sell, Il7ra, Klf2, transferrin receptor (Tfrc), and Gzmb, as the concentration of lz-FasL was titrated up (Supplemental Figure 8). Consistent with the apoptosis-inducing function of FasL, exposure to lz-FasL resulted in reduced cell yields, particularly at concentrations greater than $33 \mathrm{ng} / \mathrm{ml}$ (Figure 6C). Despite this effect, we measured a significant increase in the relative numbers of $\mathrm{T}_{\mathrm{EM}}$ cell phenotype/IFN- $\gamma^{+}$cells following lz-FasL exposure at $33 \mathrm{ng} / \mathrm{ml}$ compared with vehicle control (Figure 6D). Importantly, the increase in absolute numbers of $\mathrm{T}_{\mathrm{EM}}$ cells occurred despite this subset's enhanced susceptibly to lz-FasL-induced apoptosis relative to other subsets (Supplemental Figure 9). The differential 
A

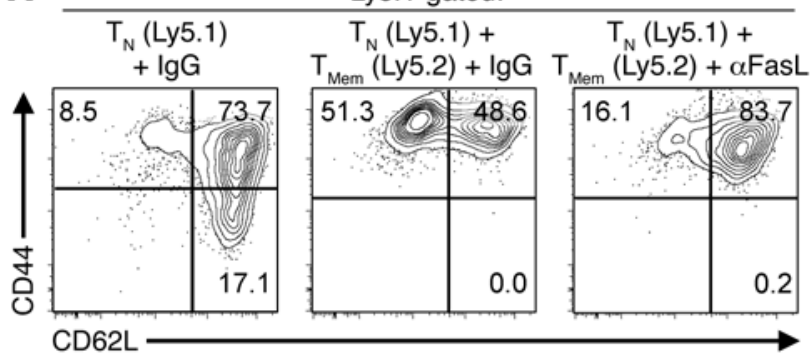

D

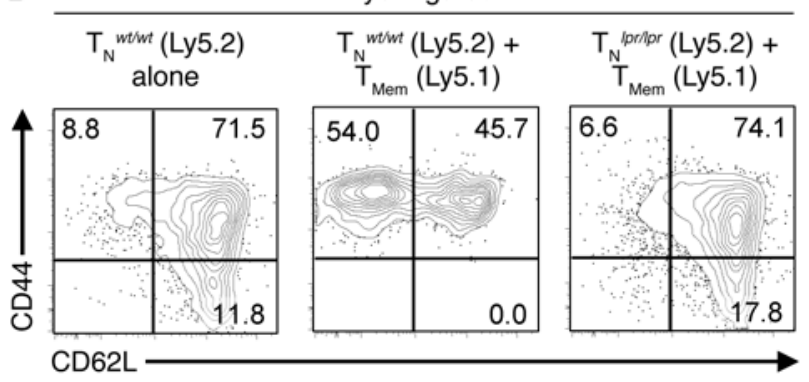

B
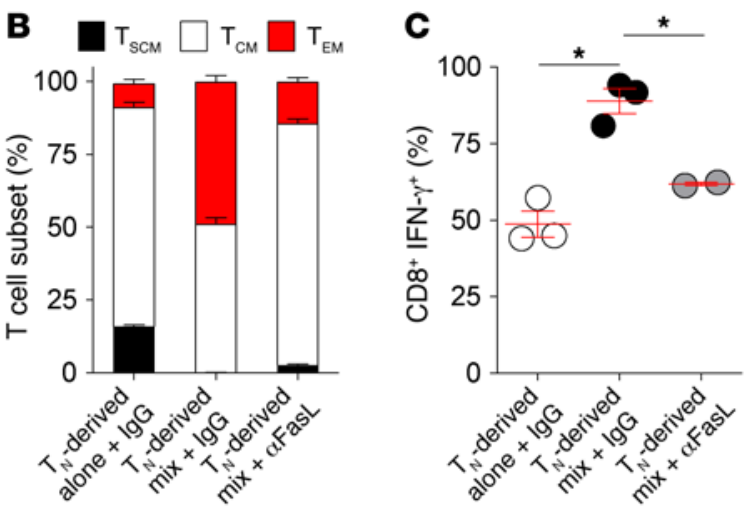

$\mathbf{E}$

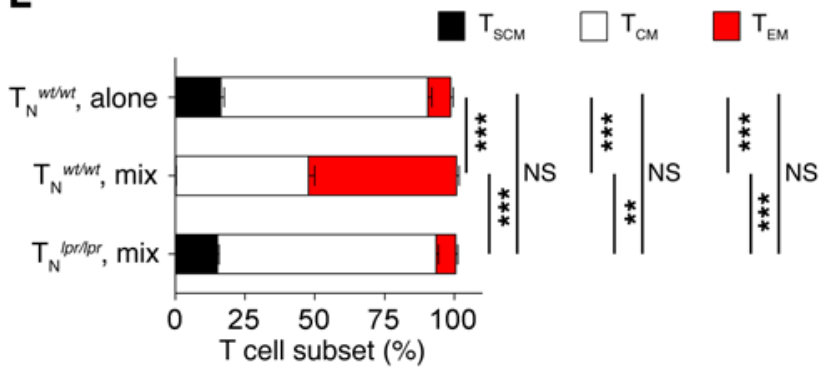

Figure 5. FasL-Fas interactions mediate precocious differentiation. (A) Representative FACS plots, (B) summary bar graph, and (C) scatter plot demonstrating T cell subset frequencies or percentage of IFN- $\gamma^{+} C D 8^{+} T$ cells 6 days following priming of Ly5.1+ $T_{N}$ alone or in a 1:1 mixture with Ly5.2 $2^{+} T_{\text {Mem }}$ with CD3/CD28-specific antibodies, IL-2, and a blocking antibody against FasL ( $\alpha$ FasL) or isotype (IgC) control. (D) FACS analysis and (E) bar graph summarizing the distribution of CD8 ${ }^{+} T$ cell subsets 6 days following priming of Ly5.2+ $W T T_{N}$ pmel- 1 ( $T_{N}{ }^{W T / W T}$ ) or $/ p r / / p r T_{N}$ pmel-1 ( $T_{N}$ Ipr//pr) cells alone or in the presence of a 1:1 mixture with WT Ly5.1 ${ }^{+} \mathrm{T}_{\mathrm{Mem}}$. All results shown as mean \pm SEM with $n=2-3$ per indicated condition or cell type. Statistical comparisons performed using an unpaired 2-tailed Student's $t$ test corrected for multiple comparisons by a Bonferroni adjustment. ${ }^{*} P<0.05 ;{ }^{* *} P<0.01$; ${ }^{* * *} P<0.001$. Data shown are representative of 14 (A and $\mathbf{B}), 4$ (C), and 3 ( $\mathbf{D}$ and $\mathbf{E})$ independently performed experiments.

death of $\mathrm{T}_{\mathrm{FM}}$ cells was not attributable to differences in surface Fas expression between memory subsets (Supplemental Figure 10), a finding consistent with published studies of Fas expression on human $\mathrm{T}_{\mathrm{Mem}}$ cell subsets (45). Collectively, these data suggested that skewing toward the $\mathrm{T}_{\mathrm{EM}}$ cell phenotype could not be accounted for solely by selective culling of $\mathrm{T}_{\mathrm{SCM}}$ and $\mathrm{T}_{\mathrm{CM}}$ cells.

We next sought to determine whether Fas-mediated cellular differentiation and cell death could be uncoupled using a genetic approach. Previous work established that Fas-induced apoptosis requires posttranslational palmitoylation of a cysteine residue located within the proximal cytoplasmic region of the receptor $(46,47)$. In cell lines, transfection of a Fas construct substituting a valine for a cysteine residue at the 194 position (C194V) prevented both Fas incorporation into membrane rafts and Fas-dependent apoptosis (46). Based on these data, a transgenic mouse expressing the FasC194V variant was generated, backcrossed to the lpr background (henceforth, FasC194V $\mathrm{V}^{l r / / p r}$ ), and used to derive CD8 ${ }^{+} \mathrm{T}$ cells for further analyses. Whereas lz-FasL caused dose-dependent death of WT CD8 ${ }^{+} \mathrm{T}$ cells, FasC194 $\mathrm{V}^{p r / p r} \mathrm{CD}^{+} \mathrm{T}$ cells were significantly protected from apoptosis induction similarly to $\operatorname{lpr} \mathrm{CD}^{+} \mathrm{T}$ cells (Figure 6E). However, unlike cells from the $l p r$ mouse, which were also protected from lz-FasL-mediated precocious differentiation, FasC194V $\mathrm{V}^{\text {lpr/pr }} \mathrm{CD} 8^{+} \mathrm{T}$ cells underwent enhanced conversion to a $\mathrm{T}_{\mathrm{EM}}$ cell phenotype similar to that of WT cells following priming with $40 \mathrm{ng} / \mathrm{ml} \mathrm{lz-FasL}$ (Figure 6, F and G). We conclude that a nonapoptotic Fas signal delivered by FasL is sufficient to induce the augmented differentiation of recently activated $\mathrm{T}_{\mathrm{N}}$ cells.
Precocious differentiation is associated with induction of Akt signaling. We next sought to determine what signals downstream of Fas contribute to precocious differentiation. Multiple signal transduction pathways have been implicated in nonapoptotic Fas signaling (39), including the phosphatidyl 3-kinase/protein kinase B (also known as Akt) pathway $(42,43)$. Given the established role of Akt in $\mathrm{CD} 8^{+} \mathrm{T}$ cell effector differentiation (48), we focused our attention on the induction of phospho-Akt (pAkt) and phospho-ribosomal protein S6 (pS6), a kinase downstream of Akt signaling in $\mathrm{T}$ cells (23). Compared with resting $\mathrm{T}_{\mathrm{N}}$ cells, naive cells activated for 24 hours with CD3/CD28-specific antibodies exhibited augmented staining with phospho-specific antibodies against both the T308 and S473 activation residues on Akt as well as pS6 (Figure 7, A-C). Importantly, when Ly5.2 ${ }^{+} \mathrm{T}_{\mathrm{N}}$ cells were primed in the presence of congenically distinguishable Ly5.1 $1^{+} \mathrm{T}_{\mathrm{Mem}}$ cells, we observed a significant increase in the staining intensity of pAkt T308, pAkt S473, and pS6 in $\mathrm{T}_{\mathrm{N}}$-gated cells. To establish whether increased pAkt content in $\mathrm{T}_{\mathrm{N}}$ cells primed with $\mathrm{T}_{\mathrm{Mem}}$ cells leads to commensurate changes in gene expression, we returned to our microarray analyses. Within 18 hours of $\mathrm{T}_{\mathrm{N}}$ cell activation in the presence of $\mathrm{T}_{\mathrm{Mem}}$ cells, we observed significant alterations in the expression of known targets of Akt signaling, including Il7r (49), sphingosine-1-phosphate receptor 1 (S1pr1) (50), Tfrc (51), hexokinase-2 (Hk2) (52), and solute carrier family 2 (Slc2a1, also known as Glut1) (ref. 53 and Figure 7D). Based on these data, we next tested to determine whether provision of lz-FasL to activated $\mathrm{T}_{\mathrm{N}}$ cells was sufficient to augment pAkt in the absence of $\mathrm{T}_{\text {Mem }}$ 
A
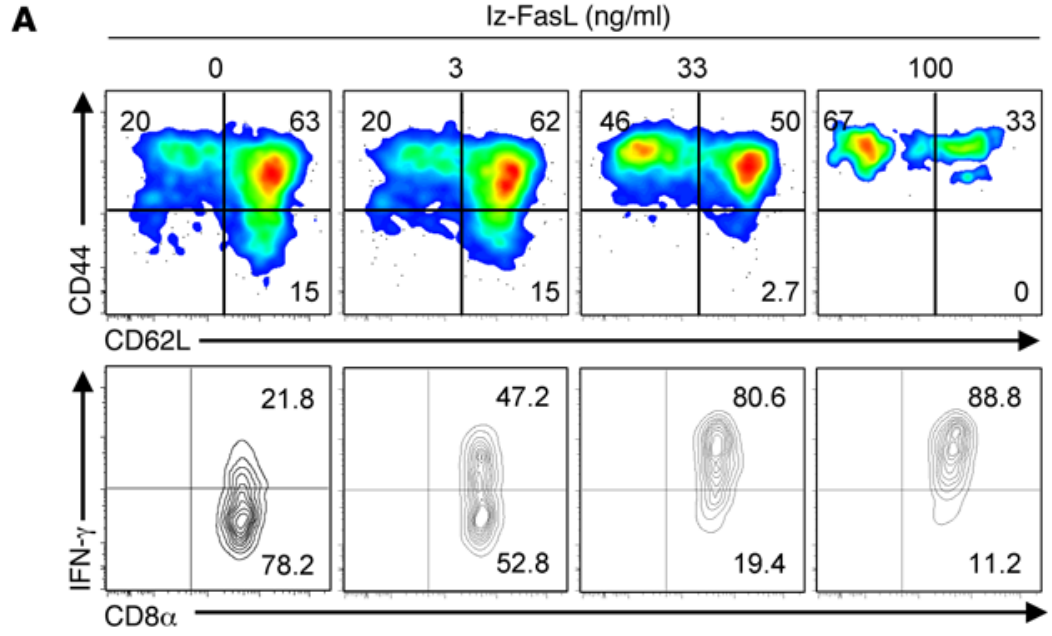

C

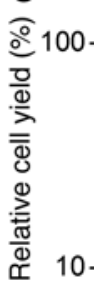
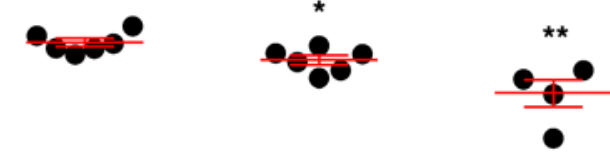

$\mathbf{E}$

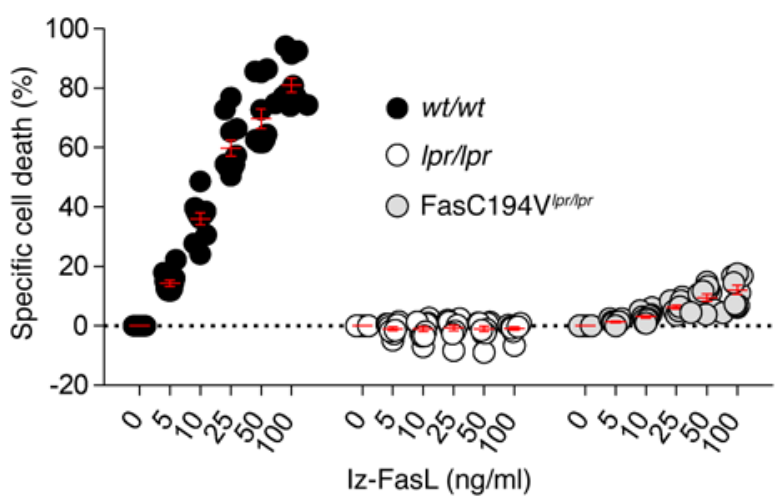

F Iz-FasL trimer WT
B
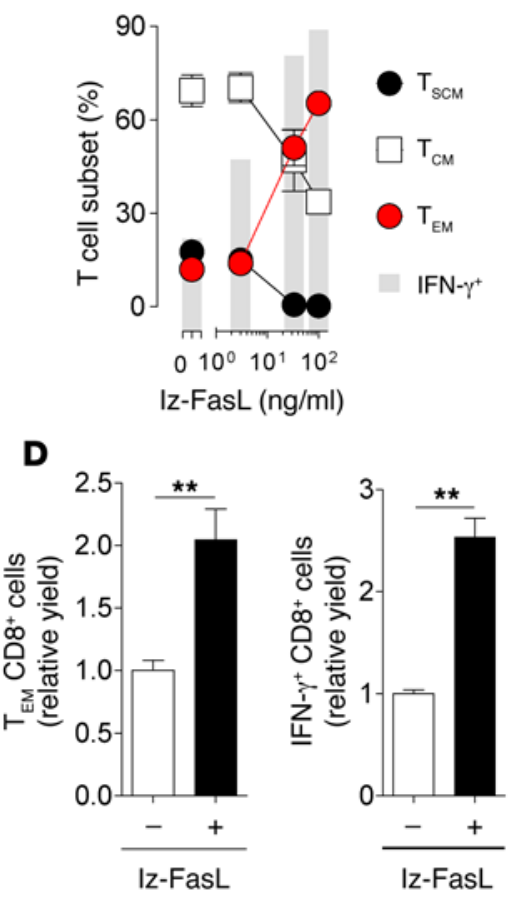
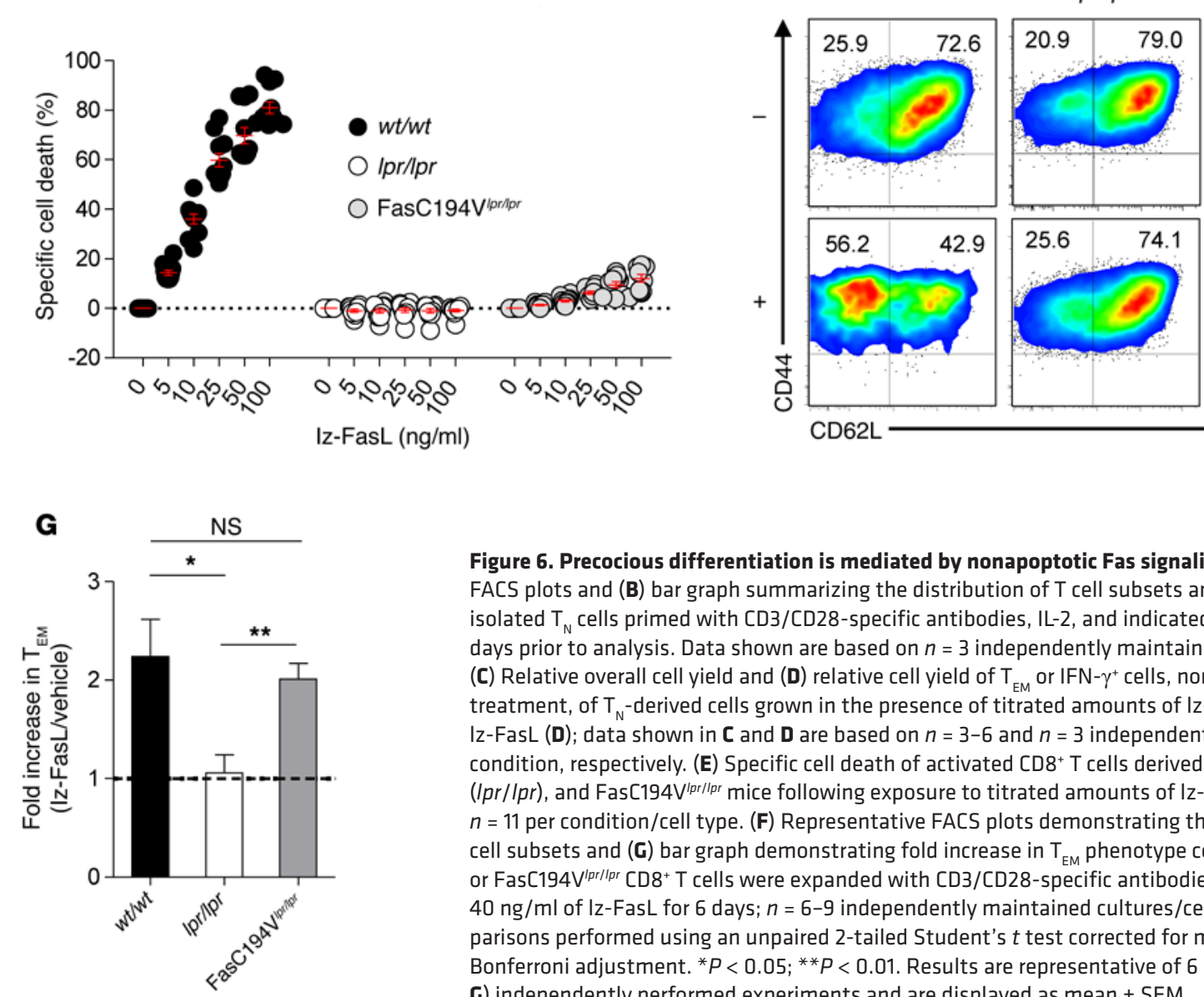

FasC194VIpropor
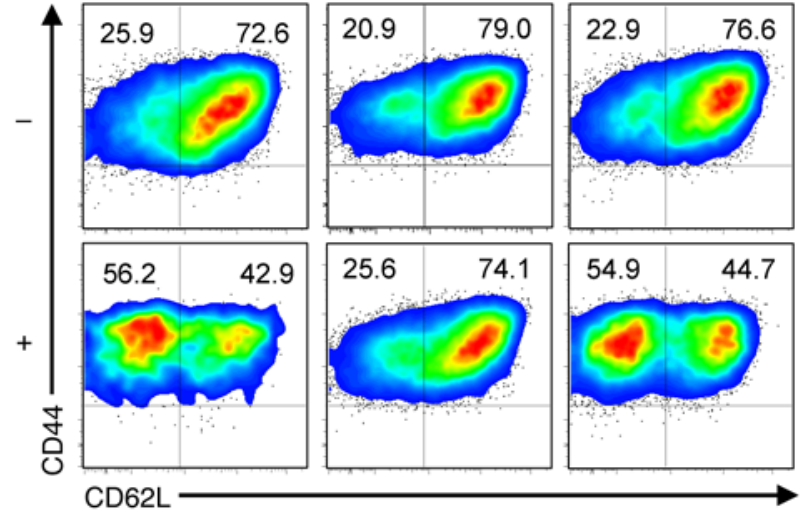

Figure 6. Precocious differentiation is mediated by nonapoptotic Fas signaling. (A) Representative FACS plots and (B) bar graph summarizing the distribution of T cell subsets and IFN- $\gamma$ production in isolated $\mathrm{T}_{\mathrm{N}}$ cells primed with CD3/CD28-specific antibodies, IL-2, and indicated doses of Iz-FasL for 6 days prior to analysis. Data shown are based on $n=3$ independently maintained cultures/condition. (C) Relative overall cell yield and (D) relative cell yield of $\mathrm{T}_{E M}$ or IFN- $\gamma^{+}$cells, normalized to no Iz-FasL treatment, of $T_{N}$-derived cells grown in the presence of titrated amounts of $\mid z$-FasL (C) or $33 \mathrm{ng} / \mathrm{ml}$ Iz-FasL (D); data shown in C and $\mathbf{D}$ are based on $n=3-6$ and $n=3$ independently maintained cultures/ condition, respectively. (E) Specific cell death of activated CD8 ${ }^{+}$T cells derived from WT (WT/WT), Lpr (Ipr/Ipr), and FasC194V $/$ pr//pr mice following exposure to titrated amounts of Iz-FasL or a vehicle control; $n=11$ per condition/cell type. (F) Representative FACS plots demonstrating the frequency of $T_{N}$-derived cell subsets and (G) bar graph demonstrating fold increase in $\mathrm{T}_{\mathrm{EM}}$ phenotype cells after $W T / W T$, Ipr/Ipr, or FasC194VIpr//pr CD8 ${ }^{+} T$ cells were expanded with CD3/CD28-specific antibodies and IL-2 alone or with $40 \mathrm{ng} / \mathrm{ml}$ of Iz-FasL for 6 days; $n=6-9$ independently maintained cultures/cell type. Statistical comparisons performed using an unpaired 2-tailed Student's $t$ test corrected for multiple comparisons by a Bonferroni adjustment. ${ }^{*} P<0.05$; ${ }^{*} P<0.01$. Results are representative of $6(\mathbf{A}), 2(\mathbf{C}-\mathbf{E})$, and 4 (F and G) independently performed experiments and are displayed as mean \pm SEM. 
A Gated on live ${ }^{+} \mathrm{CD}^{+} \mathrm{T}_{\mathrm{N}}$-derived cells:

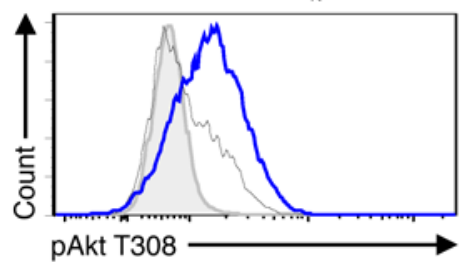

$\mathrm{T}_{\text {Mem }}$ stim

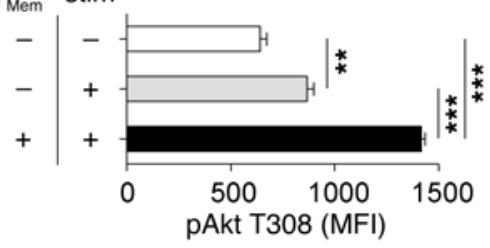

- $\mathrm{T}_{\mathrm{N}}$-derived, alone

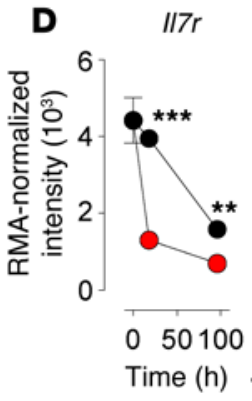

F

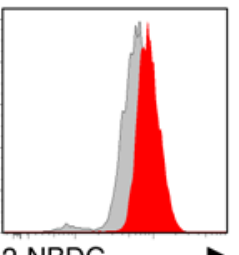

2-NBDG

$T_{N}$-derived

+ vehicle

$T_{N}$-derived

+ Iz-FasL
B

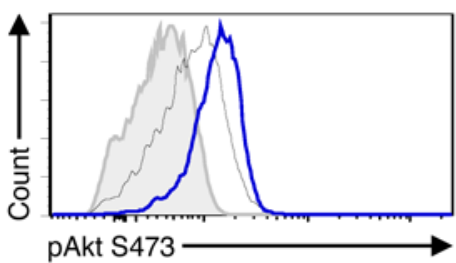

C

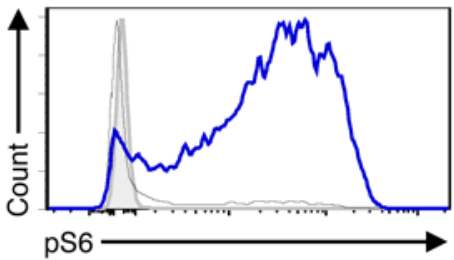

$\mathrm{T}_{\text {Mem }}$ stim

$\mathrm{T}_{\text {Mem }}$ stim
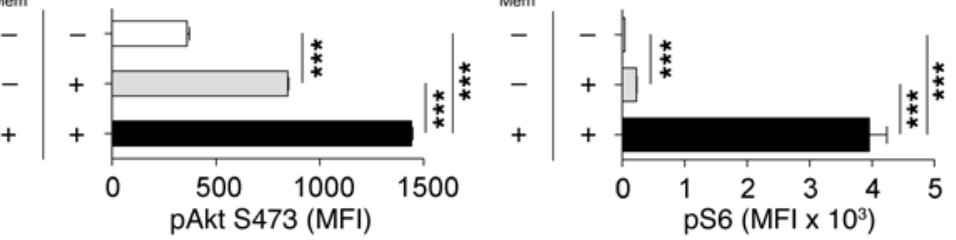

$\mathrm{T}_{\mathrm{N}}$-derived, mix
Tfrc Hk2

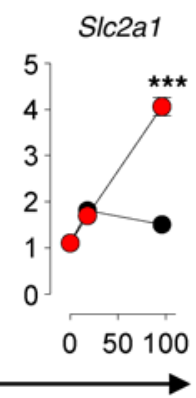

H

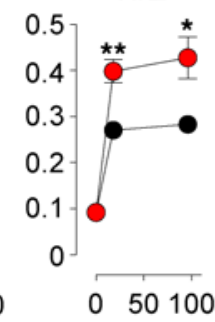

050
E

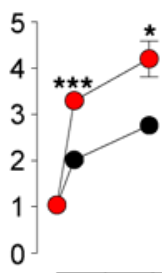

$0 \longdiv { 5 0 1 0 0 }$
G

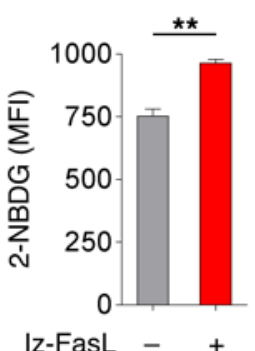

$\mathrm{T}_{\mathrm{N}}$-derived

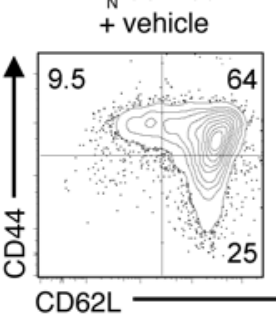

25 CD62L

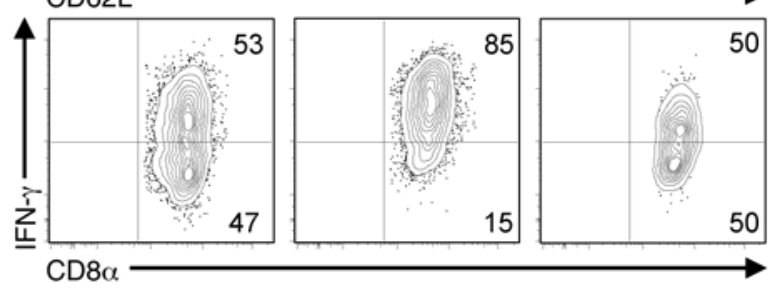

$T_{N}$, baseline

$\square \mathrm{T}_{N}$, stim alone

$\mathrm{T}_{\mathrm{N}}, \mathrm{stim}+\mathrm{T}_{\text {Mem }}$
$1 \mathrm{~T}_{\mathrm{SCM}} \square \mathrm{T}_{\mathrm{CM}} \square \mathrm{T}_{\mathrm{EM}}$

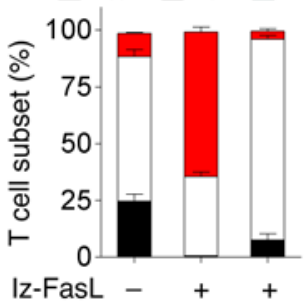

Iz-FasL -++

20

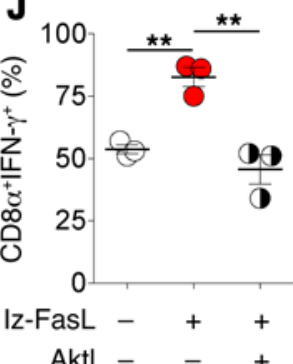

Figure 7. Precocious differentiation is associated with augmented Akt signaling. Representative FACS histograms and summary bar graphs demonstrating the mean fluorescence intensity of (A) pAkt T308, (B) pAkt S473, and (C) pS6 in Ly5.2 ${ }^{+}$CD8 ${ }^{+} T_{N}$ cells at rest or 24 hours after stimulation with CD3/ CD28-specific antibodies alone or in a 1:1 mixture with Ly5.1 $1^{+} T_{\text {Mem }}$ cells. Data shown after gating on live ${ }^{+}$Ly5.2 $2^{+}$CD8 ${ }^{+}$cells. (D) RMA-normalized intensity showing expression of II7ra, S1pr1, Tfrc, Hk2, and S/c2a1 in resting $T_{N}$ cells, $T_{N}$ cells primed alone, and $T_{N}$ cells primed in a 1:1 mixture with $T_{M e m}$ cells. (E) Western blot and densitometry analysis of pAkt T308 and GAPDH in resting $T_{N}$ or $T_{N}$ cells primed for 24 hours with CD3/CD28-specific antibodies and titrated doses of Iz-FasL. (F) Representative FACS plot and (C) summary scatter plot showing 2-NBDG expression in $T_{N}$ cells primed alone for 6 days with CD3/CD28-specific antibodies, IL-2, and Iz-FasL $(50 \mathrm{ng} / \mathrm{ml}$ ) or vehicle control. Data shown after gating on live+CD8+ lymphocytes. (H) Representative FACS plots, (I) summary bar graph demonstrating the frequency of CD8 ${ }^{+} \mathrm{T}$ cell subsets, and (J) scatter plots showing IFN- $\gamma$ production in $\mathrm{T}_{\mathrm{N}}$ cells primed with CD3/CD28-specific antibodies, IL-2, and Iz-FasL $(50 \mathrm{ng} / \mathrm{ml}$ ) in the presence or absence of an inhibitor of Akt1/2 (Aktl) for 6 days. Statistical comparisons performed using an unpaired 2-tailed Student's $t$ test corrected for multiple comparisons by a Bonferroni adjustment. ${ }^{*} P<0.05 ;{ }^{* *} P<0.01 ;{ }^{* * *} P<0.001$. All data shown are displayed as mean \pm SEM. Experiments performed with $n=3$ per condition/time point in A-D and F-J. All data shown are representative of 2 independently conducted experiments. 
A

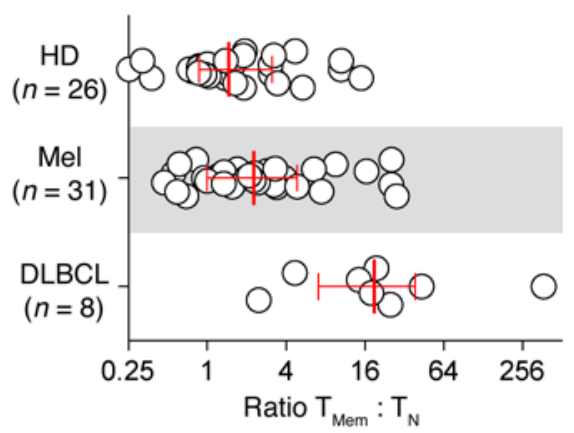

C

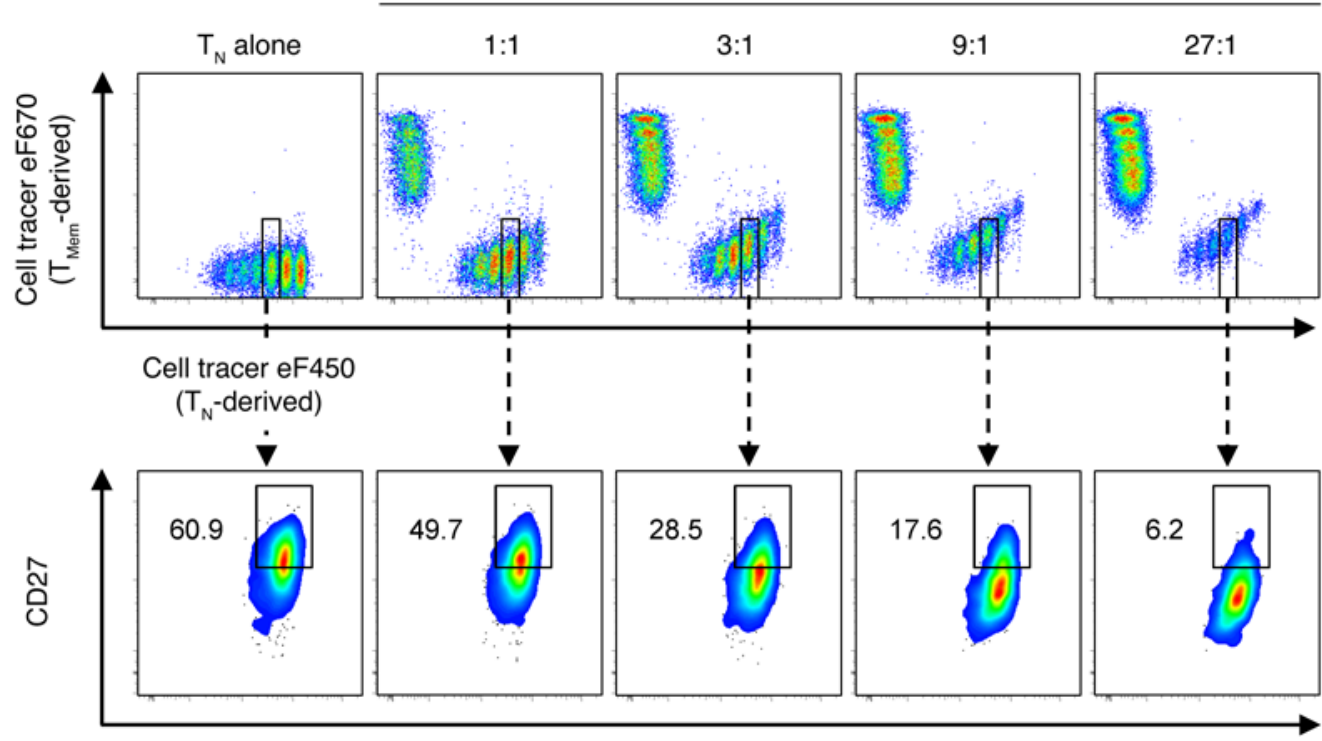

$\mathrm{T}_{\mathrm{N}}$ before stimulation

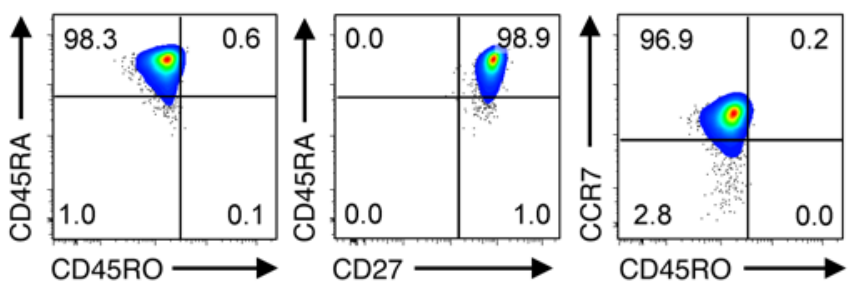

D

$\operatorname{CD} 8 \alpha$

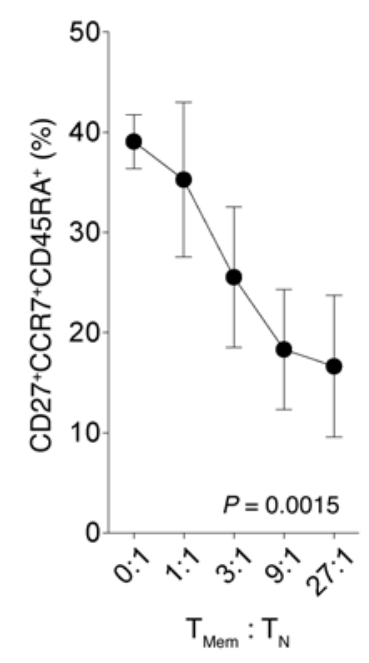

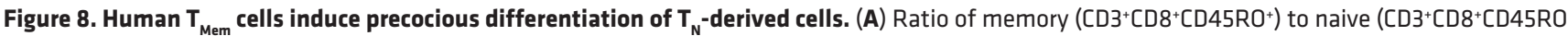
CD45RA $\left.{ }^{+} C C R 7^{+}\right) \mathrm{CD}^{+}$T cells in the peripheral circulation of HDs $(n=26)$, Mel patients $(n=31)$, or DLBCL patients $(n=8)$. Results shown as the median \pm interquartile range. (B) Representative FACS plots demonstrating the surface phenotype of isolated $T_{N}$ cells after membrane labeling with cell tracer eF450 but before stimulation. (C) Representative FACS plots demonstrating the gating strategy used to assess the division-normalized phenotype of human $\mathrm{T}_{\mathrm{N}}$-derived progeny 4 days following activation alone or in the presence of titrated ratios with $\mathrm{T}_{\mathrm{Mem}}$ cells. Naive and $\mathrm{T}_{\text {Mem }}$ cells were labeled with cell tracer eF450 or eF670, respectively, and stimulated at indicated ratios using CD3/CD28-specific antibodies and IL-2. Naive-derived cells were subsequently analyzed for the coordinate expression of CD27, CCR7, and CD45RA using Boolean gating after gating on $\mathrm{T}_{\mathrm{N}}$ cells that had diluted an equivalent amount of the cell tracer eF450 dye. (D) Summary graph demonstrating the frequency of $T_{N}$ cells that coordinately express the markers CD27 $C$ CR7 ${ }^{+}$CD45RA ${ }^{+}$after undergoing a normalized number of cell divisions plotted as a function of the ratio of $T_{M e m}$ to $T_{N}$ cells. Results shown as mean $\pm S E M$ for each condition for $n=3$ independently evaluated donors. $P=0.0015$ (repeated measures 1-way ANOVA).

cells. Whereas pAkt T308 was undetectable in resting $\mathrm{CD} 8^{+} \mathrm{T}_{\mathrm{N}}$ cells, we found that lz-FasL caused dose-dependent augmentation of this phosphorylated residue 24 hours following activation with CD3/CD28-specific antibodies (Figure 7E). Consistent with the augmented expression of $S l c 2 a 1$ and $H k 2$ in $\mathrm{T}_{\mathrm{N}}$ cells primed with $\mathrm{T}_{\mathrm{Mem}}$ cells combined with the capacity of Akt activation to enhance Glut1 surface expression (53), we measured increased accumulation of the fluorescent D-glucose analog 2-( $N$-[7-nitrobenz-2-oxa-1,3-diazol-4-yl]amino)-2-deoxyglucose (2-NBDG) in $\mathrm{T}_{\mathrm{N}}$ cells activated with lz-FasL (Figure 7, F and G). This indicated a relatively enhanced conversion to a glycolytic metabolism in $\mathrm{T}_{\mathrm{N}}$ cells exposed to lz-FasL (54). Finally, to determine whether Akt signaling directly contributed to precocious differentiation, we primed $C D 8^{+} T_{N}$ cells in the presence of $50 \mathrm{ng} / \mathrm{ml}$ of lz-FasL with or without Akt inhibitor VIII (AktI), a well-validated alloste- ric Akt inhibitor $(48,55)$. We found that AktI significantly limited lz-FasL-mediated precocious differentiation, as evidenced by a reduced accumulation of $\mathrm{T}_{\mathrm{EM}}$ cell phenotype and IFN- $\gamma^{+}$cells (Figure 7, $\mathrm{H}-\mathrm{J})$. We conclude that $\mathrm{T}_{\mathrm{Mem}}$ cell and lz-FasL-induced precocious differentiation of $\mathrm{T}_{\mathrm{N}}$ cells is associated with augmented Akt pathway activation. Pharmacologic inhibition of Akt can partially block the precocious differentiation phenotype.

Human $T_{\text {Mem }}$ cells induce precocious differentiation of $T_{N}$-derived cells. To evaluate the relevance of precocious differentiation for human ACT trials, we next tested to determine whether human $\mathrm{T}_{\mathrm{Mem}}$ cells influence the differentiation of $\mathrm{T}_{\mathrm{N}}$ cells during ex vivo cell expansion. First, we established the frequency of $\mathrm{T}_{\mathrm{Mem}}$ cells compared with $\mathrm{T}_{\mathrm{N}}$ cells in the circulation of healthy donors (HD) or patients with metastatic melanoma (Mel) and diffuse large B cell lymphoma (DLBCL), 2 malignancies where ex vivo-expanded 
A

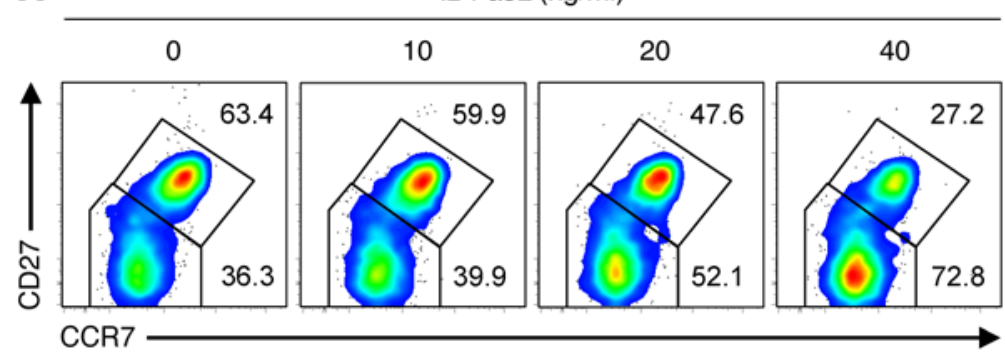

C

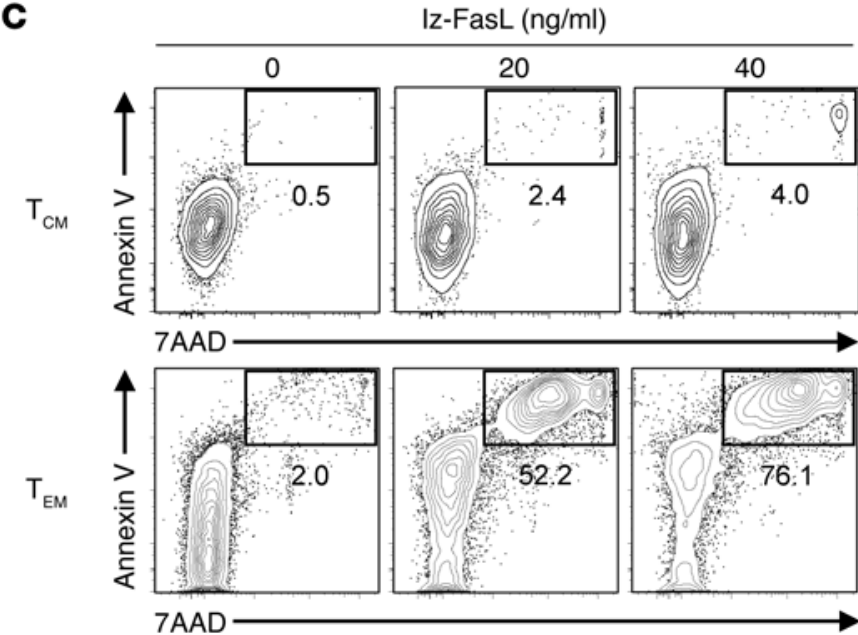

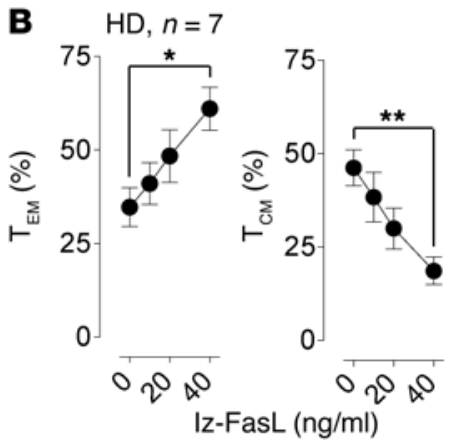

D

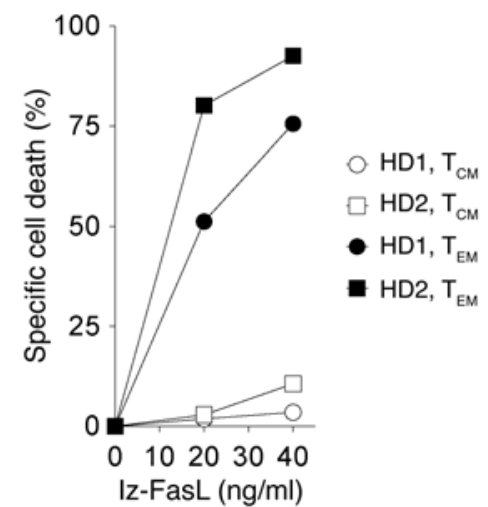

Figure 9. Fas signaling promotes the differentiation of human CD8+ $\mathbf{T}$ cells. (A) Representative FACS plots and (B) summary graph showing the distribution of CD8 ${ }^{+} \mathrm{T}$ cell subsets 7 to 10 days after peripheral blood CD8 ${ }^{+} \mathrm{T}$ cells from HD were stimulated with CD3/CD28-specific antibodies, IL-2, and indicated concentrations of Iz-FasL. Results shown after gating on viable CD8 lymphocytes from $n=7 \mathrm{HD}$. $T_{\mathrm{CM}}=\mathrm{CD} 8^{+} \mathrm{CD} 45 \mathrm{RO} \mathrm{C}^{+} \mathrm{CCR} 7^{+} \mathrm{CD} 27^{+}, T_{\mathrm{EM}}=\mathrm{CD} 8^{+} \mathrm{CD} 45 \mathrm{RO} \mathrm{C}^{+} \mathrm{CCR7}$

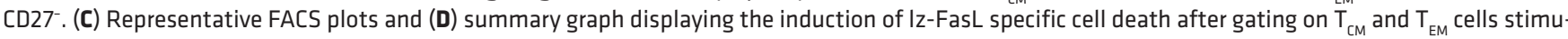
lated with indicated concentrations of Iz-FasL for 12 hours. Cells that coordinately stained for 7-AAD and annexin V were considered apoptotic. Statistical comparisons performed using an unpaired 2-tailed Student's $t$ test corrected for multiple comparisons by a Bonferroni adjustment. ${ }^{*} P<0.05 ;{ }^{* *} P<0.01$. Data shown are representative of 7 ( $\mathbf{A}$ and $\mathbf{B}$ ) and 2 ( $\mathbf{C}$ and $\mathbf{D}$ ) independently performed experiments with results displayed as mean \pm SEM.

adoptively transferred $\mathrm{T}$ cells have entered clinical trials (56-58). We found that the $\mathrm{T}_{\mathrm{Mem}}$ cell to $\mathrm{T}_{\mathrm{N}}$ cell ratio was 1 or greater in the majority of cases, with a median value of $1.5,2.3$, and 18.8 in HD, Mel patients, and DLBCL patients, respectively (Figure 8A). The increased ratio in DLBCL patients was likely due to the influence of prior lymphodepleting chemotherapy (30). To track the fate of human $\mathrm{T}_{\mathrm{N}}$ cell-derived progeny in mixed cultures, we isolated $\mathrm{T}_{\mathrm{N}}\left(\mathrm{CD}^{+}{ }^{+} \mathrm{CD} 45 \mathrm{RA}^{+} \mathrm{CD} 45 \mathrm{RO}^{-} \mathrm{CCR}^{+}\right)$and $\mathrm{T}_{\mathrm{Mem}}\left(\mathrm{CD} 8^{+} \mathrm{CD} 45 \mathrm{RA}\right.$ $\left.\mathrm{CD} 45 \mathrm{RO}^{+}\right)$cells from the same donor and labeled these subsets with alternative fluorescent membrane dyes (Figure 8B and Supplemental Figure 11A). Labeled T cells were expanded alone or together in titrated ratios using CD3/CD28-specific antibodies and IL-2. Although this approach did not allow for indelible cell tracking, we found we could reliably distinguish each population for up to 6 days.

Four days following activation, $\mathrm{T}_{\mathrm{N}}$ cells and $\mathrm{T}_{\mathrm{Mem}}$ cells lost membrane dye intensity, indicating both subsets had undergone cell division. To determine whether human $\mathrm{T}_{\mathrm{N}}$ cells expand at the same rate in the presence or absence of memory cells, we calculated the proliferation index (PI) of $\mathrm{T}_{\mathrm{N}}$-derived cells primed alone or with different ratios of $\mathrm{T}_{\mathrm{Mem}}$ cells. We discovered that human $\mathrm{T}_{\mathrm{Mem}}$ cells caused a dose-dependent increase in $\mathrm{T}_{\mathrm{N}}$ cell proliferation (Supplemental Figure 11B). To ascertain whether $\mathrm{T}_{\mathrm{Mem}}$ cells influence $\mathrm{T}_{\mathrm{N}}$ cell differentiation independently of cell prolifera- tion, we gated on $\mathrm{T}_{\mathrm{N}}$-derived cells that had undergone an equivalent number of cell divisions (Figure 8C). We then evaluated the coordinate expression of naive-associated phenotypic markers (CD27, CCR7, CD45RA) by flow cytometry using a Boolean gating strategy. We found across all donors tested that, when normalized for division history, there was a significant dose-dependent loss of $\mathrm{T}_{\mathrm{N}}$ cells $\left(\mathrm{CD} 27^{+} \mathrm{CCR} 7^{+} \mathrm{CD} 45 \mathrm{RA}^{+}\right)$as the ratio of $\mathrm{T}_{\mathrm{Mem}}$ cells was increased $(P=0.0015)$ (Figure $8 D)$. Similar conclusions were reached regardless of the generation number evaluated (data not shown). We conclude that human $\mathrm{T}_{\mathrm{Mem}}$ cells augmented both the proliferation and differentiation of $\mathrm{T}_{\mathrm{N}}$-derived cells. Further, we conclude that the rate of differentiation is enhanced even when division history is normalized.

In mice, we discovered that $\mathrm{T}_{\mathrm{Mem}}$ cell-induced precocious differentiation of $\mathrm{T}_{\mathrm{N}}$ cells was mediated by FasL. To determine whether enhanced Fas signaling augmented the differentiation of human $\mathrm{CD} 8^{+} \mathrm{T}$ cells, we primed peripheral blood $\mathrm{CD} 8^{+} \mathrm{T}$ cells from HDs with $\mathrm{CD} 3 / \mathrm{CD} 28$-specific antibodies and IL-2 alone or in the presence of titrated concentrations of lz-FasL. After 9 to 10 days, we found that all expanded cells had assumed a CD45RA $\mathrm{R}^{\mathrm{lo} /}$ $\mathrm{CD} 45 \mathrm{RO}^{+}$memory phenotype (data not shown). Using coexpression of CD27 and CCR7 (29), we characterized the ratio of $\mathrm{T}_{\mathrm{CM}}$ $\left(\mathrm{CD} 8^{+} \mathrm{CD}^{2} 5 \mathrm{RO}^{+} \mathrm{CCR}^{+} \mathrm{CD} 27^{+}\right)$to $\mathrm{T}_{\mathrm{EM}}$ cells $\left(\mathrm{CD} 8^{+} \mathrm{CD} 45 \mathrm{RO}^{+} \mathrm{CCR} 7^{-}\right.$ 
A

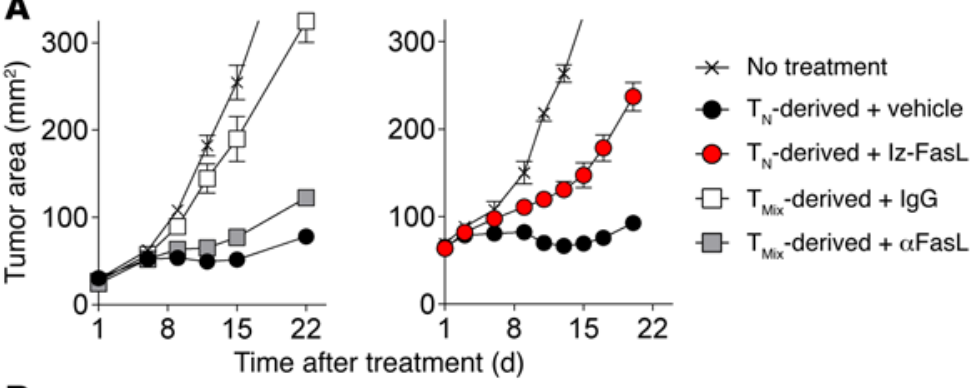

B

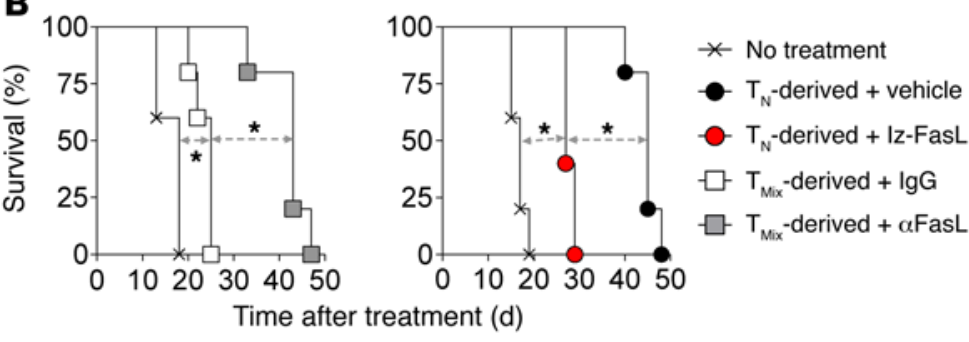

C

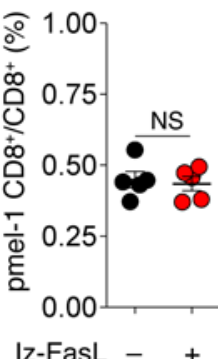

D

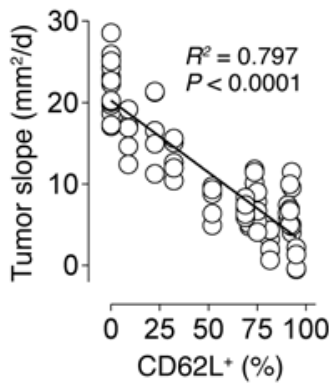

Figure 10. Fas signaling controls $\mathrm{T}$ cell differentiation and influences adoptive immunotherapy efficacy. (A) Tumor regression and (B) animal survival of mice bearing 10-day established s.c. B16 melanomas treated with $2.5 \times 10^{5} \mathrm{~T}_{\mathrm{N}}$-derived pmel-1 cells primed alone, with Iz-FasL $(50 \mathrm{ng} / \mathrm{ml})$, or with $\mathrm{T}_{\mathrm{Mem}}$ in the presence of $\alpha$ FasL or IgG control. Viable cells were isolated using a density separation media before infusion. All treated mice received 6 Gy irradiation prior to cell infusion in addition to i.v. rVV-gp100 and 3 days of i.p. IL-2. Tumor treatment experiments performed with $n=5$ mice/group. $\mathrm{T}_{\text {Mix }} \mathrm{T}_{\mathrm{N}}$ cells primed with $\mathrm{T}_{\text {Mem }}$ cells in a 1:1 mixture. (C) Engraftment efficiency of Thy1.1 $1^{+} T_{N}$-derived pmel-1 cells $\left(3 \times 10^{5}\right)$ primed alone or with Iz-FasL 18 hours following i.v. adoptive transfer into nonirradiated Ly5.2+ hosts; $n=5$ mice/group. (D) Correlation between the slope of tumor growth and CD62L expression at the time of cell transfer on $\mathrm{T}_{\mathrm{N}}$-derived pmel-1 cells primed alone with either Iz-FasL ( $50 \mathrm{ng} / \mathrm{ml}$ ), vehicle control, or with $\mathrm{T}_{\text {Men }}$ and either $\alpha$ FasL or IgG. Pooled results from 2 independently performed experiments displayed using $n=4-10$ mice per condition. Statistical comparisons performed using an unpaired 2-tailed Student's $t$ test or log-rank test for animal survival. ${ }^{*} P<0.05$. Data shown are representative of 2 independent experiments with results displayed as mean $\pm \mathrm{SEM}$.
CD27-). Consistent with experiments using mouse $\mathrm{T}$ cells, we found that augmenting Fas signaling using lz-FasL in HD cells caused a significant and dose-dependent accumulation of the more-differentiated $\mathrm{T}_{\mathrm{EM}}$ cell subset and an attrition of $\mathrm{T}_{\mathrm{CM}}$ cells (Figure 9, A and B). These changes were not attributable to differences in proliferation, as T cells expanded in lz-FasL and vehicle control diluted a membrane-associated dye similarly (Supplemental Figure 12A). Moreover, analysis of the surface phenotype of T cells that had undergone an identical number of divisions revealed that lz-FasL exposure resulted in a more-differentiated phenotype compared with cells expanded in vehicle control (Supplemental Figure 12B). Consistent with the apoptosis-inducing functions of Fas, lz-FasL resulted in a reduced cell yield at concentrations of $20 \mathrm{ng} / \mathrm{ml}$ or more (Supplemental Figure 12C). However, at lower concentrations of lz-FasL, we measured differences in the distribution of $\mathrm{T}$ cell subsets while expanding similar numbers of cells. To exclude that the observed changes in human $\mathrm{CD} 8^{+} \mathrm{T}$ cell subset composition were due to selective $\mathrm{T}_{\mathrm{CM}}$ cell killing, we evaluated the induction of apoptosis (as measured by coordinate 7-AAD and annexin $\mathrm{V}$ staining) in $\mathrm{T}_{\mathrm{CM}}$ and $\mathrm{T}_{\mathrm{EM}}$ cell subsets following stimulation with titrated amounts of lz-FasL (Figure 9, C and D). Similar to both our mouse data and previously reported data in human $\mathrm{CD}^{+}$ T cells (45), we found that $\mathrm{T}_{\mathrm{EM}}$ cells were far more sensitive to Fasinduced apoptosis compared with the $\mathrm{T}_{\mathrm{CM}}$ cell subset. Collectively, we conclude that human $\mathrm{T}_{\mathrm{N}}$ cells, like mouse $\mathrm{T}_{\mathrm{N}}$ cells, undergo accelerated differentiation when primed in the presence of $\mathrm{T}_{\mathrm{Mem}}$ cells or augmented Fas signaling.
Fas signaling controls $T$ cell differentiation and antitumor efficacy. $\mathrm{T}_{\mathrm{Mem}}$-induced precocious differentiation of $\mathrm{T}_{\mathrm{N}}$-derived cells resulted in impaired antitumor efficacy in mice. Given our findings that precocious differentiation is mediated by FasL-Fas interaction, we next tested to determine whether modulation of Fas signaling could influence the therapeutic potential of adoptively transferred $\mathrm{T}_{\mathrm{N}}$-derived cells. We therefore primed pmel-1 $\mathrm{T}_{\mathrm{N}}$ cells in the presence of congenically distinguishable $\mathrm{T}_{\mathrm{Mem}}$ cells in combination with $\alpha$ FasL or IgG control. In addition, we also primed $T_{N}$ cells alone with lz-FasL or vehicle control. Following expansion, equal numbers of viable $\mathrm{CD}^{+} \mathrm{T}$ cells obtained using a density separation media for each culture condition were adoptively transferred into sublethally irradiated mice bearing 10-day established B16 melanomas in combination with rVV-gp100 and IL-2. We found that FasL blockade during $\mathrm{T}_{\mathrm{N}}$ cell expansion in the presence of $\mathrm{T}_{\mathrm{Mem}}$ cells significantly improved tumor regression $(P=0.009)$ and animal survival $(P<0.05)$, nearly rescuing the in vivo antitumor potential of isolated $\mathrm{T}_{\mathrm{N}}$ cells (Figure 10, $\mathrm{A}$ and $\mathrm{B}$ ). In contrast, FasL blockade had no impact on the antitumor efficacy of isolated $\mathrm{T}_{\mathrm{N}}$ cells expanded without $\mathrm{T}_{\mathrm{Mem}}$ cells (Supplemental Figure 13). Conversely, augmenting Fas signaling using lz-FasL during $\mathrm{T}_{\mathrm{N}}$ cell priming significantly impaired tumor regression $(P<0.01)$ and animal survival $(P<0.05)$. The differences in treatment efficacy of lz-FasL primed $\mathrm{T}_{\mathrm{N}}$ cells were not attributable to impaired cell engraftment, as a similar frequency of cells was recovered 18 hours after transfer (Figure 10C). Overall, we found a significant inverse linear correlation between the state of $\mathrm{T}$ cell differentiation, as 
measured by CD62L expression on transferred T cells primed with FasL blockade or augmentation, and tumor growth $\left(R^{2}=0.797\right.$, $P<0.0001$; Figure 10D). These data suggest that FasL-mediated perturbations in $\mathrm{T}$ cell differentiation were highly correlated with the antitumor treatment efficacy of transferred $\mathrm{CD} 8^{+} \mathrm{T}$ cells. We conclude that the negative influence of $\mathrm{T}_{\mathrm{Mem}}$ cell-induced precocious differentiation on the treatment efficacy of adoptively transferred $\mathrm{T}_{\mathrm{N}}$-derived cells in mice is mediated by a FasL-Fas interaction that can be rescued with FasL blockade during cell expansion.

\section{Discussion}

Herein, we present evidence using both human and mouse cells that antigen-experienced $\mathrm{CD}^{+} \mathrm{T}$ cells directly influence naive cell differentiation both during cell expansion ex vivo and following adoptive cotransfer in vivo. This process, which we have termed precocious differentiation, serves to synchronize the functional, transcriptional, and metabolic state of $\mathrm{T}_{\mathrm{N}}$-derived progeny with that of $\mathrm{T}_{\mathrm{Mem}}$ cells. Consequently, precocious differentiation leads to an attrition of the highly potent $\mathrm{T}_{\mathrm{SCM}}$ and $\mathrm{T}_{\mathrm{CM}}$ populations and an accumulation of $\mathrm{T}_{\mathrm{EM}}$ cells, resulting in the impaired proliferation, persistence, and antitumor treatment efficacy of adoptively transferred T cells.

In multiple preclinical models, minimally differentiated $\mathrm{T}_{\mathrm{N}}$, $\mathrm{T}_{\mathrm{SCM}}$, and $\mathrm{T}_{\mathrm{CM}}$ cell subsets exhibit superior persistence $(12,18$, $27,59-62)$ and enhanced antitumor $(18,27,59)$, antibacterial (62), and antiviral responses following ACT compared with the highly differentiated $\mathrm{T}_{\mathrm{EM}}$ cell and effector $\mathrm{T}$ cell $\left(\mathrm{T}_{\mathrm{Eff}}\right)$ populations. Despite these data, the vast majority of current ACT trials utilize unfractionated $\mathrm{T}$ cell populations $(2,20)$. Largely, this is based on an assumption that having at least some representation of the less-differentiated subsets in the starting population used to generate therapeutic T cells is sufficient to convey their desirable attributes. Our data directly challenge this notion by demonstrating that $\mathrm{T}_{\mathrm{N}}$ cells must either be isolated from $\mathrm{T}_{\mathrm{Mem}}$ cells prior to cell expansion or have their capacity to respond to $\mathrm{T}_{\mathrm{Mem}}$ cell-mediated signaling disrupted to preserve their full therapeutic potential. Accomplishing these goals at a clinical scale might be done using several strategies. These include isolating defined $\mathrm{T}$ cell subsets from peripheral blood using serial positive enrichments with reversible Fab streptamers (63), employing a combination of negative and positive magnetic bead isolations (64), and antagonizing Fas or Akt signaling (55). Based on the data in this manuscript, we have initiated a human clinical trial registered at ClinicalTrials.gov (NCT02062359) in which $\mathrm{T}_{\mathrm{N}}$ cells are enriched relative to $\mathrm{T}_{\mathrm{Mem}}$ cells using magnetic bead isolation of CD62Lexpressing cells prior to gene engineering with a TCR recognizing the cancer-germline antigen NY-ESO-1. Results from this and other planned clinical trials will determine whether ACT of naiveenriched $\mathrm{T}$ cells results in superior clinical outcomes compared with transfer of unselected $\mathrm{T}$ cell populations.

Mechanistically, we identified the TNF superfamily member FasL, which is expressed on $\mathrm{T}_{\text {Mem }}$ cells but not $\mathrm{T}_{\mathrm{N}}$ cells acutely following activation, as the mediator of precocious differentiation. FasL was both necessary and sufficient to induce the phenomenon. Provision of $\mathrm{lz}$-FasL recapitulated precocious differentiation in the absence of $\mathrm{T}_{\mathrm{Mem}}$ cells, while antibody blockade of FasL or use of $\mathrm{T}$ cells from Fas-deficient $l p r$ mice prevented precocious differentiation. Reverse signaling by FasL in T cells has been observed under some conditions (65). Our findings that T cells derived from $l p r$ mice or were protected from precocious differentiation combined with the ability of lz-FasL to mediate the phenomenon excluded reverse signaling as a mechanism in our system.

While Fas is conventionally known as a death receptor, its ability to mediate nonapoptotic functions has been documented in a variety of tissues (39), including T cells (40). We provide several lines of evidence that our findings were not attributable solely to Fas-induced apoptosis. First, we determined that $\mathrm{T}_{\mathrm{EM}}$ cells, the population that accumulates in response to augmented Fas signaling, was most sensitive to Fas-mediated apoptosis relative to other $\mathrm{T}$ cell subsets in both mice and humans. This finding is in agreement with previously reported results (45). Thus, selective culling of $\mathrm{T}_{\mathrm{SCM}}$ and $\mathrm{T}_{\mathrm{CM}}$ cells could not account for the skewing toward the $\mathrm{T}_{\mathrm{EM}}$ cell population. Second, using $\mathrm{CD} 8^{+} \mathrm{T}$ cells derived from a transgenic mouse expressing a FasC194V mutant receptor, we provide genetic evidence that Fas-mediated cell death and cellular differentiation can be uncoupled by impairing the ability of the receptor to undergo posttranslational lipid modification. Although further studies are required to resolve the precise signaling cascade necessary for Fas-induced precocious differentiation, we found that both $\mathrm{T}_{\mathrm{Mem}}$ cells and lz-FasL augmented Akt signaling in $\mathrm{T}_{\mathrm{N}}$ cells. Similarly to previously reported Akt-dependent functions of canonical costimulatory molecules such as CD28 (66), augmenting Fas signaling in $\mathrm{T}_{\mathrm{N}}$ cells enhanced cellular differentiation and promoted a glycolytic metabolism. Conversely, inhibition of Akt using a well-validated allosteric inhibitor largely prevented lz-FasL-induced differentiation of $\mathrm{T}_{\mathrm{N}}$ cells, further implicating Akt activation in Fas-mediated differentiation. These findings parallel recent reports of Akt-mediated nonapoptotic Fas signaling in glioblastoma (42) and neuronal stem cells (43).

We determined that the capacity to induce precocious differentiation was a generalized property of antigen-experienced $\mathrm{T}$ cells, regardless of whether they were $\mathrm{T}_{\mathrm{CM}}$ or $\mathrm{T}_{\mathrm{EM}}$ cells. These findings were associated with a permissive epigenetic signature at the FasL locus in both $\mathrm{T}_{\mathrm{CM}}$ and $\mathrm{T}_{\mathrm{EM}}$ cell subsets relative to $\mathrm{T}_{\mathrm{N}}$ cells. Further, we resolved that precocious differentiation required both cell activation and direct cell contact between $\mathrm{T}$ cell subsets to occur. Separation of $\mathrm{T}_{\mathrm{N}}$ and $\mathrm{T}_{\mathrm{Mem}}$ cells by a semipermeable membrane prevented the phenomenon and transfer of $\mathrm{T}_{\mathrm{Mem}}$ cell-derived supernatant to $\mathrm{T}_{\mathrm{N}}$ cells could not reproduce the effect. Recent multiphoton microscopy studies have revealed that $\mathrm{T}_{\mathrm{N}}$ and $\mathrm{T}_{\mathrm{CM}}$ cells form stable clusters together in vivo around antigen-bearing targets (67, 68). Additionally, while lymphoid-trafficking of the CD62L- $\mathrm{T}_{\mathrm{EM}} /$ $\mathrm{T}_{\text {Eff }}$ cell subsets is limited in the steady state, inflamed lymph nodes become permissive to entry of these cells (69). Thus, there is evidence that $\mathrm{T}_{\mathrm{N}}$ and $\mathrm{T}_{\mathrm{Mem}}$ cells can physically interact with one another in vivo. Whether such $\mathrm{T}_{\mathrm{N}}$ and $\mathrm{T}_{\mathrm{Mem}}$ cell interactions might also influence the response to intracellular pathogens or vaccines under certain conditions is the subject of future work.

A prior study evaluated the influence of preexisting $\mathrm{T}$ cell memory on the recruitment and differentiation of $\mathrm{T}_{\mathrm{N}}$ cells in vivo (35). Unlike current ACT clinical protocols in which large numbers of $\mathrm{T}$ cells are infused in an attempt to gain control over tumor replication, this study evaluated the transfer of a limiting number of $\mathrm{T}_{\mathrm{N}}$ cells (500 cells) in hosts containing 100- to 1,000-fold greater numbers of $\mathrm{T}_{\mathrm{Mem}}$ cells. Under these conditions, $\mathrm{T}_{\mathrm{Mem}}$ cells numeri- 
cally outcompeted $\mathrm{T}_{\mathrm{N}}$ cells for access to limited antigen and cytokines, thus curtailing the differentiation of $\mathrm{T}_{\mathrm{N}}$ cells. However, how $\mathrm{T}_{\text {Mem }}$ cells influence $\mathrm{T}_{\mathrm{N}}$ cell differentiation when cells are coinfused in the relatively large numbers and ratios typically used in adoptive immunotherapies has previously not been addressed. Consistent with our ex vivo cell expansion data, we found that cotransfer of $\mathrm{T}_{\mathrm{Mem}}$ cells caused accelerated $\mathrm{T}_{\mathrm{N}}$ cell differentiation into a terminally differentiated KLRG1 $1^{+} \mathrm{CD} 27^{\mathrm{lo}}$ phenotype despite an attenuated proliferative burst. The decreased expansion of antitumor $\mathrm{T}_{\mathrm{N}}$ cells primed with $\mathrm{T}_{\mathrm{Mem}}$ cells in vivo likely reflected their accelerated conversion to antigen-experienced subsets that are known to have a reduced proliferative capacity relative to $\mathrm{T}_{\mathrm{N}}$ cells following poxvirus vaccination (70). Most importantly, cotransfer of $\mathrm{T}_{\mathrm{Mem}}$ cells impaired the full in vivo antitumor efficacy of $\mathrm{T}_{\mathrm{N}}$ cells.

The magnitude of accelerated $\mathrm{T}_{\mathrm{N}}$ cell differentiation caused by $\mathrm{T}_{\mathrm{Mem}}$ cells was remarkably sensitive to the ratio of the 2 subsets such that an exponential relationship existed between the extent to which $\mathrm{T}_{\mathrm{N}}$-derived progeny entered the $\mathrm{T}_{\mathrm{EM}} / \mathrm{T}_{\mathrm{EFF}}$ pool and the starting proportion of $\mathrm{T}_{\mathrm{Mem}}$ to $\mathrm{T}_{\mathrm{N}}$ cells. In this manner, moredifferentiated $\mathrm{T}$ cell subsets have the capacity to synchronize their phenotype, function, and gene expression with less-differentiated subsets. Some unicellular organisms exhibit collective decision making through cell-cell communication once a threshold concentration of members detect an environmental stress (71). This process, termed quorum sensing, allows individual members of a community to exhibit collectivist behaviors in order to coordinate expression of energetically expensive processes involved in virulence and differentiation (71). While quorum sensing has been theorized to be relevant to understanding lymphocyte behavior $(72,73)$, our data add to growing experimental data demonstrating that, under certain circumstances, $\mathrm{T}$ cells can also exhibit collectivist behaviors $(74,75)$.

In conclusion, we describe what we believe to be a previously unrecognized $\mathrm{T}$ cell- $\mathrm{T}$ cell interaction whereby antigen-experienced $\mathrm{CD} 8^{+} \mathrm{T}$ cells drive $\mathrm{T}_{\mathrm{N}}$ cell differentiation during priming through a contact-dependent mechanism involving a nonapoptotic Fas-FasL interaction. The net influence of this process synchronizes $\mathrm{T}_{\mathrm{N}}$ cell behavior with that of $\mathrm{T}_{\mathrm{Mem}}$ cells, affecting the functional, transcriptional, and metabolic differentiation of $\mathrm{T}_{\mathrm{N}}$-derived progeny. For adoptive immunotherapies, where there is a strong inverse correlation between $\mathrm{T}$ cell differentiation and antitumor efficacy, the implications of our findings are clear: $\mathrm{T}_{\mathrm{Mem}}$ cause significantly enhanced differentiation of $\mathrm{T}_{\mathrm{N}}$ cells, impairing in vivo antitumor efficacy. Therefore, strategies that disrupt quorum-like behavior among $\mathrm{T}$ cell subsets might provide a new means of enhancing the effectiveness of T cell-based immunotherapies.

\section{Methods}

Mouse strains and animal studies. Adult (6 to 12 weeks old) female C57BL/6 (B6; Ly5.2+), B6.SJL-Ptprc ${ }^{a}$ Pep3 $3^{b} /$ BoyJ (Ly5.1+), B6.PLThy $1^{a} /$ CyJ (Thy1.1 $1^{+}$), B6.MRL-Fas ${ }^{\text {lpr }} / \mathrm{J}$ (lpr) (44), B6.129S7-Rag1 $1^{\text {tmIMom }} / \mathrm{J}$ (Rag), B6.Cg-Thy1 ${ }^{a} / \mathrm{Cy} \operatorname{Tg}$ (TcraTcrb)8Rest/J (pmel-1) (24), and B6-Tg(TcraTcrb)1100Mjb/J (OT-1) (76) CD8 ${ }^{+}$TCR transgenic mice were all purchased from the Jackson Laboratory. Transgenic mice harboring the Fas C194V mutant receptor were generated via BAC containing the Fas locus, with the $\mathrm{C} 194 \mathrm{~V}$ generated by recombineering. These mice were backcrossed to $l p r$ mice on a B6 background. Fas-
C194V $\mathrm{V}^{l p r / p r}$ mice were backcrossed to homozygosity for both the $l p r$ Fas allele and the C194V Fas transgene. Where indicated, pmel-1 and OT-1 mice were crossed to Thy1.1, Ly5.1, Rag, or Rag $\times$ lpr backgrounds. All mice were maintained under specific pathogen-free conditions.

Evaluation of vaccine-induced and antitumor immunity. Adult female B6 mice were implanted by s.c. injection with $4 \times 10^{5} \mathrm{~B} 16$ $\left(\mathrm{H}-2 \mathrm{D}^{\mathrm{b}}\right)$ cells, a spontaneous gp100 ${ }^{+}$murine melanoma cell line obtained from the NCI tumor repository. Ten days later, tumor-bearing mice received $6 \mathrm{~Gy}$ total body irradiation. Treated mice received i.v. injection of indicated doses and subsets of pmel-1 CD8 ${ }^{+} \mathrm{T}$ cells in combination with $2 \times 10^{7}$ pfu of a previously described recombinant vaccinia virus (rVV-gp100) (24) (rVV-gp100) and $12 \mu \mathrm{g}$ IL-2 (Prometheus) administered twice daily by i.p. injection for a total of 6 doses. All tumor measurements were performed in a blinded fashion.

Antibodies and flow cytometry. Mouse cells were stained with fluorochrome-conjugated antibodies against combinations of the following surface and intracellular antigens after Fc receptor blockade (2.4G2): CD8 $\alpha$ (clone 53-6.7), CD27 (clone LG.3A10), CD44 (clone IM7), CD45.1(clone A20), CD45.2 (clone 104), CD62L (clone MEL14), CD90.1 (clone OX-7), CD90.2 (clone 53-2.1), CD95 (clone Jo2), CD122 (clone TM- $\beta 1)$, CD178 (clone MFL3), IFN- $\gamma$ (clone XMG1.2), KLRG-1 (clone 2F1), and Sca-1 (clone D7) (all purchased from BD Biosciences). Fluorochrome conjugates against pS6 S235/236 (D57.2.2E), pAkt T308 (C31E5E), and pAkt S473 (D9E) were obtained from Cell Signaling Technologies. Human cells were stained with combinations of the following fluorochrome-conjugated antibodies: CCR7 (150503), CD28 (CD28.2), CD45RO (UCHL1), CD8 (SK1) (BD Biosciences) or CD27 (M-T271), CD45RA (HI100), and CD62L (DREG-56) (BioLegend). Stimulation of $\mathrm{T}$ cells for intracellular cytokine staining was accomplished using Leukocyte Activation Cocktail containing phorbol myristate acetate and ionomycin in combination with brefeldin A and monensin solution (BD Biosciences). Apoptosis and specific cell death in defined $\mathrm{T}$ cell subsets was assessed using fluorochrome-conjugated annexin $\mathrm{V}$ and 7-AAD (both from BD Biosciences), as previously described (45). Where indicated, $\mathrm{T}_{\mathrm{N}}$-derived and $\mathrm{T}_{\mathrm{Mem}}$-derived subsets were reisolated for additional analyses by FACS sorting to greater than 92\% purity using FACS sorting or magnetic bead isolation. Cell viability was determined using PI exclusion in FACS-sorting experiments or fixable live/dead cells (Invitrogen) for diagnostic experiments. For FACS-based glucose uptake assays, we incubated $\mathrm{CD} 8^{+} \mathrm{T}$ cells with $100 \mu \mathrm{M}$ 2-NBDG (Invitrogen) for 2 hours before measuring by FACS, as previously described (54). Flow cytometric data were acquired using either BD FACSCanto II, LSR, or LSRFortessa cytometers (BD Biosciences). FACS data, including calculation of PI, were analyzed with FlowJo Version 9.7 software (TreeStar).

Isolation and generation of mouse and human $C D 8^{+} T$ cell subsets. Mouse $\mathrm{T}_{\mathrm{N}}$ cells were isolated either by using a MACS CD8 ${ }^{+}$negative selection kit (Miltenyi Biotech) in combination with a 1:300 dilution of biotin-conjugated anti-CD44 antibody or by FACS sorting CD $44^{\text {lo }} \mathrm{CD}^{2} 2 \mathrm{~L}^{\text {hi }} \mathrm{CD} 8^{+} \mathrm{T}$ cells using FACSAria (BD Biosciences). Mouse $\mathrm{T}_{\mathrm{Mem}}$ cells were generated by in vitro differentiation (as previously described) or by adoptive transfer of congenically distinguishable Thy $1.1^{+}$or Ly5.1 $1^{+}$pmel-1 CD $8^{+}$T cells into Ly5.2 ${ }^{+}$WT mice, where recipient mice were vaccinated with $\mathrm{rVV}$-gp100 $\left(2 \times 10^{7} \mathrm{PFU}\right)$ and vaccine-induced $\mathrm{T}_{\mathrm{CM}}\left(\mathrm{CD} 44^{\text {hi }}{ }^{\mathrm{CD}} 62 \mathrm{~L}^{+}\right)$or $\mathrm{T}_{\mathrm{EM}}\left(\mathrm{CD} 44^{\text {hi }} \mathrm{CD} 62 \mathrm{~L}^{-}\right)$adoptively transferred subsets were isolated by FACs sorting more than 28 days later $(27,77)$. Human T cells were obtained either by leukapheresis or 
venipuncture and prepared over Ficoll-Hypaque gradient (LSM; ICN Biomedicals Inc.). Human $\mathrm{T}_{\mathrm{N}}$ cells and $\mathrm{T}_{\mathrm{Mem}}$ cells were obtained by magnetic bead isolation using the EasySep Human Naive CD8 ${ }^{+} \mathrm{T}$ Cell and Memory CD8 ${ }^{+} \mathrm{T}$ Cell Enrichment Kits, respectively (STEMCELL Technologies). Fate tracking of $\mathrm{T}_{\mathrm{N}}$ and $\mathrm{T}_{\mathrm{Mem}}$ cells was accomplished by labeling cells with Cell Proliferation Dye eFluor 450 and Cell Proliferation Dye eFluor 670, respectively (eBioscience).

Activation and expansion of $C D 8^{+} T$ cells. Both mouse and human $\mathrm{T}_{\mathrm{N}}$ cells with or without $\mathrm{T}_{\mathrm{Mem}}$ cells were activated and expanded at indicated ratios in 96-well round-bottom plates coated with $2 \mu \mathrm{g} / \mathrm{ml}$ of CD3-specific and $1 \mu \mathrm{g} / \mathrm{ml}$ of soluble CD28-specific antibodies (clones 145-2C11 and 37.51; BD Biosciences) in culture media containing $5 \mathrm{ng} /$ $\mathrm{ml}$ (mouse) or $20 \mathrm{ng} / \mathrm{ml}$ (human) of IL-2 at a final density of $1 \times 10^{5}$ cells/well. Where indicated, $\mathrm{T}$ cells were cultured with specified concentrations of lz-FasL, a previously described recombinant oligomerized form of FasL (45), or $10 \mu \mathrm{g} \mathrm{ml}^{-1}$ of either a blocking antibody against FasL (MFL3; BD Biosciences) or IgG (A19-3; BioLegend). In some experiments, cells were also cultured with $1 \mu \mathrm{M}$ of Akt Inhibitor VIII (Calbiochem) dissolved in DMSO (Sigma-Aldrich). Where indicated, $\mathrm{T}_{\mathrm{N}}$-derived and $\mathrm{T}_{\mathrm{Mem}}$-derived subsets were reisolated for additional analyses by FACS sorting to more than $95 \%$ purity using FACS sorting or magnetic bead isolation. Transwell experiments were conducted in 24-well plates using $0.4 \mu \mathrm{m}$ inserts (Corning Costar) with $\mathrm{T}_{\mathrm{N}}$ cells alone or in combination with $\mathrm{T}_{\mathrm{Mem}}$ cells either in the bottom well or in the Transwell insert.

Cytokine release assays. We pulsed $\mathrm{B} 6$ splenocytes with indicated concentrations of hgp100 ${ }_{25-33}$ peptide and incubated cells with $\mathrm{T}_{\mathrm{N}}{ }^{-}$ derived pmel- $1 \mathrm{CD} 8^{+} \mathrm{T}$ cells at a $1: 1$ ratio overnight at $37^{\circ} \mathrm{C}$. Supernatants were analyzed for mouse IFN- $\gamma$ by ELISA (R\&D Systems).

qPCR and Western blot. For qPCR analysis, $\mathrm{CD} 8^{+} \mathrm{T}$ cell subsets were FACS sorted directly into RNAprotect Cell Reagent, and RNA was extracted using the QiaShredders and RNeasy Mini Kits (all from QIAGEN). cDNA was synthesized using the High Capacity RNA-tocDNA kit (Applied Biosystems), and qPCR was performed on an ABI 7500 Fast Instrument (Applied Biosystems). Gene expression was quantified using probes targeting Ccr7, Cd27, Gzmb, Il7ra, Klf2, Sell, Tbx21, Tcf7, Tfrc, and Prdm1 (Applied Biosystems). For Western blot analysis, $\mathrm{CD} 8^{+} \mathrm{T}$ cells were sorted into FCS and subsequently lysed in protease inhibitor containing RIPA buffer (Cell Signaling Technology). Protein was quantified using the Bio-Rad protein assay. We separated $30 \mu \mathrm{g}$ of total protein on a $4 \%$ to $12 \%$ SDS-PAGE gel followed by standard immunoblotting with antibodies to pAktT308 (C31E5E; Cell Signaling Technology), GAPDH (AB2302; EMD Millipore), and horseradish peroxidase-conjugated goat antibodies to mouse and rabbit IgG (sc-2005 and sc-2004; Santa Cruz Biotechnology Inc.). Blots were developed using chemiluminescence (Thermo Fisher Scientific) and acquired using the ChemiDoc system (Bio-Rad Laboratories).

Microarray analyses and ChIP-seq. Gene-expression levels were determined using GeneChip Mouse Gene 1.0 ST arrays (Affymetrix) according to the manufacturer's protocol. $300 \mathrm{ng}$ of total RNA was used as starting material for cRNA amplification using the WT Expression Kit (Life Technologies) according to the manufacturer's protocol. cDNA was reverse transcribed, fragmented, labeled using the GeneChip WT Terminal Labeling Kit (Affymetrix), and hybridized on the arrays for 18 hours according to the manufacturer's directions. Arrays were stained and washed in the Fluidics Station 400 (Affymetrix) and scanned (Affymetrix 7G). Array data were imported into the Partek Genomic Suite using robust multichip analysis (RMA) normalization after background subtraction. One-way ANOVA was used to identify differentially expressed genes among the $4 \mathrm{~T}$ cell subtypes with a significant cut-off of pFDR $<0.01$. Differentially expressed probe sets were selected using a FDR cut-off of 0.01 without specifying a FC criterion. ChIP-seq assays were performed as previously described (55). Briefly, $2 \times 10^{7} \mathrm{~T}$ cell subsets isolated by FACS sorting were treated with MNase to generate approximately $20 \%$ dinucleosomes and $80 \%$ mononucleosomes. Antibodies against H3K4me3 (ab8580; Abcam) and H3K27me3 (07-449; Upstate) were used for immunoprecipitation. The ChIP DNA fragments were blunt ended, ligated to Solexa adaptors, and sequenced with the Illumina $1 G$ Genome Analyzer with mapping to the mouse genome (build mm10) using Bowtie software. All original microarray data were deposited in the NCBI's Gene Expression Omnibus (GEO GSE56344, GSE67825, and GSE67881).

Statistics. The products of perpendicular tumor diameters were plotted as the mean \pm SEM for each data point, and tumor treatment graphs were compared by using the Wilcoxon rank sum test and analysis of animal survival assessed using a log-rank test. Regression analysis of the slope of tumor regression as a function of CD62 $\mathrm{L}^{+}$cells among Fas-modulated $\mathrm{CD} 8^{+} \mathrm{T}$ cells was performed as described previously (78). For all other experiments, data were compared using either an unpaired 2-tailed Student's $t$ test corrected for multiple comparisons by a Bonferroni adjustment or repeated measures 1-way ANOVA, as indicated. In all cases, $P$ values of less than 0.05 were considered significant. Statistics were calculated using Prism 5 GraphPad software (GraphPad Software Inc.).

Study approval. Animal experiments were conducted with the approval of the NCI and NIAMS Animal Use and Care Committees. All anonymous NIH Blood Bank donors and cancer patients providing human samples were enrolled in clinical trials approved by the NIH Clinical Center and NCI institutional review boards. Each patient signed an informed consent form and received a patient information form prior to participation.

\section{Author contributions}

CAK, CDS, AJL, TNY, ACC, CO, MR, RR, YJ, RLE, MS, JGC, DCP, ZAB, DC, ZY, PM, AG, SKT, SP, HL, RMS, and NPR designed and/ or performed experiments. CAK, CDS, TNY, MR, ACC, FMM, and $\mathrm{EW}$ analyzed data. JGC, LG, SAR, and RMS edited the manuscript. CAK and NPR wrote the manuscript.

\section{Acknowledgments}

We thank A. Mixon and S. Farid of the NCI Surgery Branch Flow Cytometry Unit for help with flow cytometry sorting. This work was supported by the Intramural Research Programs of the NCI and NIAMS, the Center for Cancer Research of the NIH (ZIA BC011586 and ZIA BC010763), and the NIH Center for Regenerative Medicine. Additional support was provided by gifts from Li Jinyuan and the Tiens Charitable Foundation and the Milstein Family Foundation.

Address correspondence to: Christopher A. Klebanoff, 10 Center Drive, Building 10/CRC, Room 3W-5816, Bethesda, Maryland 20892-1201, USA. Phone: 301.451.6912; E-mail: klebanoc@ mail.nih.gov. 
1. Maus MV, Fraietta JA, Levine BL, Kalos M, Zhao $\mathrm{Y}$, June $\mathrm{CH}$. Adoptive immunotherapy for cancer or viruses. Annu Rev Immunol. 2014;32:189-225.

2. Jensen MC, Riddell SR. Design and implementation of adoptive therapy with chimeric antigen receptor-modified T cells. Immunol Rev. 2014;257(1):127-144.

3. Rosenberg SA, Restifo NP. Adoptive cell transfer as personalized immunotherapy for human cancer. Science. 2015;348(6230):62-68.

4. Sadelain M. T-cell engineering for cancer immunotherapy. Cancer J. 2009;15(6):451-455.

5. Leen AM, Heslop HE, Brenner MK. Antiviral T-cell therapy. Immunol Rev. 2014;258(1):12-29.

6. Bollard CM, Rooney CM, Heslop HE. T-cell therapy in the treatment of post-transplant lymphoproliferative disease. Nat Rev Clin Oncol. 2012;9(9):510-519.

7. Jena B, Dotti G, Cooper LJ. Redirecting T-cell specificity by introducing a tumor-specific chimeric antigen receptor. Blood. 2010;116(7):1035-1044

8. Kershaw MH, Westwood JA, Darcy PK. Geneengineered T cells for cancer therapy. Nat Rev Cancer. 2013;13(8):525-541.

9. June $\mathrm{CH}$, Blazar BR, Riley JL. Engineering lymphocyte subsets: tools, trials and tribulations. Nat Rev Immunol. 2009;9(10):704-716.

10. Dotti G, Gottschalk S, Savoldo B, Brenner MK. Design and development of therapies using chimeric antigen receptor-expressing T cells. Immunol Rev. 2014;257(1):107-126.

11. Hinrichs CS, et al. Adoptively transferred effector cells derived from naive rather than central memory $\mathrm{CD} 8^{+} \mathrm{T}$ cells mediate superior antitumor immunity. Proc Natl Acad Sci U S A. 2009;106(41):17469-17474.

12. Cieri N, et al. IL-7 and IL-15 instruct the generation of human memory stem $\mathrm{T}$ cells from naive precursors. Blood. 2013;121(4):573-584.

13. Hinrichs CS, et al. Human effector CD ${ }^{+} \mathrm{T}$ cells derived from naive rather than memory subsets possess superior traits for adoptive immunotherapy. Blood. 2011;117(3):808-814.

14. Casati A, et al. Clinical-scale selection and viral transduction of human naive and central memory $\mathrm{CD} 8^{+} \mathrm{T}$ cells for adoptive cell therapy of cancer patients. Cancer Immunol Immunother. 2013;62(10):1563-1573.

15. Xu Y, et al. Closely related T-memory stem cells correlate with in vivo expansion of CAR. Blood. 2014;123(24):3750-3759.

16. Rosenberg SA, et al. Durable complete responses in heavily pretreated patients with metastatic melanoma using T-cell transfer immunotherapy. Clin Cancer Res. 2011;17(13):4550-4557.

17. Louis CU, et al. Antitumor activity and longterm fate of chimeric antigen receptor-positive $\mathrm{T}$ cells in patients with neuroblastoma. Blood. 2011:118(23):6050-6056.

18. Gattinoni L, et al. A human memory T cell subset with stem cell-like properties. Nat Med. 2011;17(10):1290-1297.

19. Linnemann C, Schumacher TN, Bendle GM. T-cell receptor gene therapy: critical parameters for clinical success. J Invest Dermatol. 2011;131(9):1806-1816.

20. Klebanoff CA, Gattinoni L, Restifo NP. Sorting through subsets: which T-cell populations medi- ate highly effective adoptive immunotherapy? JImmunother. 2012;35(9):651-660.

21. Sabatos CA, et al. A synaptic basis for paracrine interleukin-2 signaling during homotypic $\mathrm{T}$ cell interaction. Immunity. 2008;29(2):238-248.

22. Gerard A, et al. Secondary T cell-T cell synaptic interactions drive the differentiation of protective CD8 ${ }^{+}$T cells. Nat Immunol. 2013;14(4):356-363.

23. Maciver NJ, Michalek RD, Rathmell JC. Metabolic regulation of T lymphocytes. Аnпи Rev Immunol. 2013;31:259-283.

24. Overwijk WW, et al. Tumor regression and autoimmunity after reversal of a functionally tolerant state of self-reactive $\mathrm{CD} 8^{+} \mathrm{T}$ cells. J Exp Med. 2003;198(4):569-580.

25. Brentjens RJ, et al. CD19-targeted T cells rapidly induce molecular remissions in adults with chemotherapy-refractory acute lymphoblastic leukemia. Sci Transl Med. 2013;5(177):177ra38.

26. Kalos M, et al. T cells with chimeric antigen receptors have potent antitumor effects and can establish memory in patients with advanced leukemia. Sci Transl Med. 2011;3(95):95ra73.

27. Gattinoni L, et al. Wnt signaling arrests effector $T$ cell differentiation and generates $\mathrm{CD} 8^{+}$memory stem cells. Nat Med. 2009;15(7):808-813.

28. Gattinoni L, Klebanoff CA, Restifo NP. Paths to stemness: building the ultimate antitumour $\mathrm{T}$ cell. Cancer. 2012;12(10):671-684

29. Rufer N, et al. Ex vivo characterization of human $\mathrm{CD} 8^{+} \mathrm{T}$ subsets with distinct replicative history and partial effector functions. Blood. 2003;102(5):1779-1787.

30. Mackall CL, et al. Distinctions between CD8 ${ }^{+}$ and $\mathrm{CD} 4^{+} \mathrm{T}$-cell regenerative pathways result in prolonged T-cell subset imbalance after intensive chemotherapy. Blood.1997;89(10):3700-3707.

31. Schober SL, Kuo CT, Schluns KS, Lefrancois L, Leiden JM, Jameson SC. Expression of the transcription factor lung Kruppel-like factor is regulated by cytokines and correlates with survival of memory $\mathrm{T}$ cells in vitro and in vivo. J Immunol. 1999;163(7):3662-3667.

32. Rao RR, Li Q, Gubbels Bupp MR, Shrikant PA. Transcription factor Foxo1 represses T-betmediated effector functions and promotes memory CD8(+) T cell differentiation. Immunity. 2012;36(3):374-387.

33. Joshi NS, et al. Inflammation directs memory precursor and short-lived effector $\mathrm{CD} 8(+) \mathrm{T}$ cell fates via the graded expression of T-bet transcription factor. Immunity. 2007;27(2):281-295.

34. Rutishauser RL, et al. Transcriptional repressor Blimp-1 promotes CD8(+) T cell terminal differentiation and represses the acquisition of central memory $\mathrm{T}$ cell properties. Immunity. 2009;31(2):296-308.

35. Martin MD, Wirth TC, Lauer P, Harty JT, Badovinac VP. The impact of pre-existing memory on differentiation of newly recruited naive CD8 T cells. J Immunol. 2011;187(6):2923-2931.

36. Kedl RM, et al. T cells compete for access to antigen-bearing antigen-presenting cells. JExp Med. 2000;192(8):1105-1113.

37. Croft M. The role of TNF superfamily members in T-cell function and diseases. Nat Rev Immunol. 2009;9(4):271-285.

38. Russ BE, et al. Distinct epigenetic signatures delineate transcriptional programs during virusspecific CD8(+) T cell differentiation. Immunity. 2014;41(5):853-865.

39. Peter ME, et al. The CD 95 receptor: apoptosis revisited. Cell. 2007;129(3):447-450.

40. Alderson MR, et al. Fas transduces activation signals in normal human T lymphocytes. J Exp Med. 1993;178(6):2231-2235.

41. Desbarats J, Newell MK. Fas engagement accelerates liver regeneration after partial hepatectomy. Nat Med.2000;6(8):920-923.

42. Kleber S, et al. Yes and PI3K bind CD95 to signal invasion of glioblastoma. Cancer Cell. 2008;13(3):235-248.

43. Corsini NS, et al. The death receptor CD95 activates adult neural stem cells for working memory formation and brain repair. Cell Stem Cell. 2009;5(2):178-190.

44. Watanabe-Fukunaga R, Brannan CI, Copeland NG, Jenkins NA, Nagata S. Lymphoproliferation disorder in mice explained by defects in Fas antigen that mediates apoptosis. Nature. 1992;356(6367):314-317.

45. Ramaswamy M, et al. Specific elimination of effector memory $\mathrm{CD} 4^{+} \mathrm{T}$ cells due to enhanced Fas signaling complex formation and association with lipid raft microdomains. Cell Death Differ. 2011;18(4):712-720.

46. Chakrabandhu K, et al. Palmitoylation is required for efficient Fas cell death signaling. EMBO J. 2007;26(1):209-220.

47. Feig C, Tchikov V, Schutze S, Peter ME. Palmitoylation of CD95 facilitates formation of SDSstable receptor aggregates that initiate apoptosis signaling. EMBO J. 2007;26(1):221-231.

48. Macintyre AN, et al. Protein kinase B controls transcriptional programs that direct cytotoxic $\mathrm{T}$ cell fate but is dispensable for $\mathrm{T}$ cell metabolism. Immunity. 2011;34(2):224-236.

49. Kerdiles YM, et al. Foxo1 links homing and survival of naive $\mathrm{T}$ cells by regulating $\mathrm{L}$-selectin, CCR7 and interleukin 7 receptor. Nat Immunol. 2009;10(2):176-184.

50. Fabre S, et al. FOXO1 regulates L-Selectin and a network of human $\mathrm{T}$ cell homing molecules downstream of phosphatidylinositol 3-kinase. J Immunol. 2008;181(5):2980-2989.

51. Kelly AP, et al. Notch-induced T cell development requires phosphoinositide-dependent kinase 1. EMBO J. 2007;26(14):3441-3450.

52. John S, Weiss JN, Ribalet B. Subcellular localization of hexokinases I and II directs the metabolic fate of glucose. PLoS One. 2011;6(3):e17674.

53. Rathmell JC, Fox CJ, Plas DR, Hammerman PS, Cinalli RM, Thompson CB. Akt-directed glucose metabolism can prevent Bax conformation change and promote growth factor-independent survival. Mol Cell Biol. 2003;23(20):7315-7328.

54. Sukumar M, et al. Inhibiting glycolytic metabolism enhances $\mathrm{CD} 8^{+} \mathrm{T}$ cell memory and antitumor function. JClin Invest. 2013;123(10):4479-4488.

55. Crompton JG, et al. Akt inhibition enhances expansion of potent tumor-specific lymphocytes with memory cell characteristics. Cancer Res. 2015;75(2):296-305.

56. Jensen MC, et al. Antitransgene rejection responses contribute to attenuated persistence of adoptively transferred CD20/CD19- 
specific chimeric antigen receptor redirected $\mathrm{T}$ cells in humans. Blood Marrow Transplant. 2010;16(9):1245-1256.

57. Robbins PF, et al. Tumor regression in patients with metastatic synovial cell sarcoma and melanoma using genetically engineered lymphocytes reactive with NY-ESO-1.JClin Oncol. 2011;29(7):917-924.

58. Kochenderfer JN, et al. Chemotherapy-refractory diffuse large B-cell lymphoma and indolent B-cell malignancies can be effectively treated with autologous $\mathrm{T}$ cells expressing an antiCD19 chimeric antigen receptor. JClin Oncol. 2015;33(6):540-549.

59. Klebanoff CA, et al. Central memory self/ tumor-reactive $\mathrm{CD} 8^{+} \mathrm{T}$ cells confer superior antitumor immunity compared with effector memory T cells. Proc Natl Acad Sci U S A. 2005;102(27):9571-9576.

60. Wang X, Berger C, Wong CW, Forman SJ, Riddell SR, Jensen MC. Engraftment of human central memory-derived effector $\mathrm{CD} 8^{+} \mathrm{T}$ cells in immunodeficient mice. Blood. 2011;117(6):1888-1898.

61. Berger C, Jensen MC, Lansdorp PM, Gough M, Elliott C, Riddell SR. Adoptive transfer of effector $\mathrm{CD}^{+} \mathrm{T}$ cells derived from central memory cells establishes persistent $\mathrm{T}$ cell memory in primates. Invest. 2008;118(1):294-305.

62. Graef P, et al. Serial transfer of single-cellderived immunocompetence reveals stemness of CD8(+) central memory T cells. Immunity.
2014;41(1):116-126.

63. Stemberger C, et al. Novel serial positive enrichment technology enables clinical multiparameter cell sorting. PLoS One. 2012;7(4):e35798.

64. Terakura S, Yamamoto TN, Gardner RA, Turtle CJ, Jensen MC, Riddell SR. Generation of CD19chimeric antigen receptor modified $\mathrm{CD} 8^{+} \mathrm{T}$ cells derived from virus-specific central memory $\mathrm{T}$ cells. Blood. 2012;119(1):72-82.

65. Sun M, Ames KT, Suzuki I, Fink PJ. The cytoplasmic domain of Fas ligand costimulates TCR signals. J Immunol. 2006;177(3):1481-1491.

66. Frauwirth KA, et al. The CD28 signaling pathway regulates glucose metabolism. Immunity. 2002;16(6):769-777.

67. Sung JH, et al. Chemokine guidance of central memory $\mathrm{T}$ cells is critical for antiviral recall responses in lymph nodes. Cell. 2012;150(6):1249-1263.

68. Chtanova T, et al. Dynamics of T cell, antigenpresenting cell, and pathogen interactions during recall responses in the lymph node. Immunity. 2009;31(2):342-355.

69. Guarda G, et al. L-selectin-neagtive CCR7effector and memory $\mathrm{CD} 8^{+} \mathrm{T}$ cells enter reactive lymph nodes and kill dendritic cells. Nat Immunol. 2007;8(7):743-752.

70. Martin MD, Condotta SA, Harty JT, Badovinac VP. Population dynamics of naive and memory CD8 $\mathrm{T}$ cell responses after antigen stimulations in vivo. J Immunol. 2012;188(3):1255-1265.
71. Rutherford ST, Bassler BL. Bacterial quorum sensing: its role in virulence and possibilities for its control. Cold Spring Harb Perspect Med. 2012;2(11):a012427.

72. Butler TC, Kardar M, Chakraborty AK. Quorum sensing allows $\mathrm{T}$ cells to discriminate between self and nonself. Proc Natl Acad Sci U S A. 2013;110(29):11833-11838.

73. Reynolds J, Amado IF, Freitas AA, Lythe G, Molina-París C. A mathematical perspective on CD4 T cell quorum-sensing. J Theor Biol. 2014;347:160-175.

74. Thaventhiran JE, et al. Activation of the Hippo pathway by CTLA-4 regulates the expression of Blimp-1 in the CD8 ${ }^{+}$T cell. Proc Natl Acad Sci U S A. 2012;109(33):E2223-E2229.

75. Amado IF, et al. IL-2 coordinates IL-2-producing and regulatory T cell interplay. JExp Med. 2013;210(12):2707-2720.

76. Hogquist KA, Jameson SC, Heath WR, Howard JL, Bevan MJ, Carbone FR. T cell receptor antagonist peptides induce positive selection. Cell. 1994;76(1):17-27.

77. Klebanoff CA, et al. Determinants of successful $\mathrm{CD} 8^{+} \mathrm{T}$-cell adoptive immunotherapy for large established tumors in mice. Cancer Res. 2011;17(16):5343-5352.

78. Gattinoni L, et al. Acquisition of full effector function in vitro paradoxically impairs the in vivo antitumor efficacy of adoptively transferred $\mathrm{CD} 8^{+}$ T cells. J Clin Invest. 2005;115(6):1616-1626. 